\title{
Random Transect with Adaptive Clustering Sampling Design - ArcPad Applet Manual
}

Vickie M. Backus, Lisa J. Rew, Bruce D. Maxwell, and

September 2011

Matthew G. Hohmann 



\title{
Random Transect with Adaptive Clustering Sampling Design - ArcPad Applet Manual
}

\author{
Vickie M. Backus, Lisa J. Rew, and Bruce D. Maxwell \\ Department of Land Resources and Environmental Science \\ Montana State University \\ Bozeman, MT 59717 \\ Matthew G. Hohmann \\ Construction Engineering Research Laboratory \\ US Army Engineer Research and Development Center \\ 2902 Newmark Drive \\ Champaign, IL 61822
}

Final report

Approved for public release; distribution is unlimited.
Prepared for Department of the Army
Office of the Director of Environmental Programs
600 Army Pentagon
Washington, DC 20310-0600




\section{Abstract}

Non-native invasive plant species (NIS) pose a significant threat to native biological diversity. Their management and control are mandated by Executive Order 13112 on all federal lands in the United States, including Army training lands.

A key component of any NIS management strategy is knowing the distribution of NIS across the management landscape. Survey or sampling methods are often needed because Army installations are too large to inventory completely. Efficient sampling is crucial because early-detection, rapid-response management approaches rely on detection of newly established (but rare) NIS populations. Adaptive sampling is an alternative to conventional sampling that capitalizes on the spatial clustering of biological populations. Adaptive sampling has the potential to be efficient at sampling rare and clustered populations, but its use has been limited by a lack of tools to aid implementation in the field.

This manual describes an adaptive cluster sampling design called the Random Transect with Adaptive Clustering Sampling Design (RTAC) and a user-friendly global positioning system (GPS) interface developed to aid implementation of the sampling design in the field. The GPS user interface described here is a customized application developed for ESRI's ArcPad ${ }^{\circledR}$ mobile geographical information software (GIS) for field applications.

DISCLAIMER: The contents of this report are not to be used for advertising, publication, or promotional purposes. Citation of trade names does not constitute an official endorsement or approval of the use of such commercial products. All product names and trademarks cited are the property of their respective owners. The findings of this report are not to be construed as an official Department of the Army position unless so designated by other authorized documents. 


\section{Table of Contents}
Abstract ii
List of Figures and Table............................................................................................................

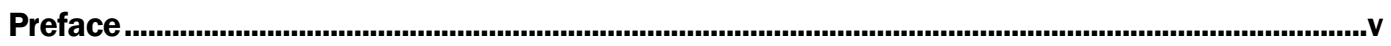

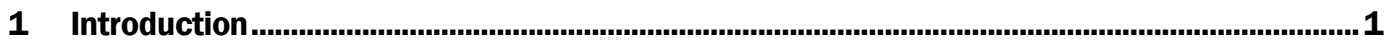

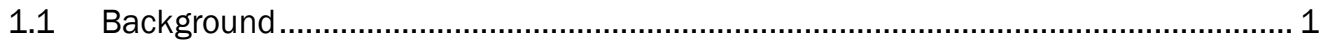

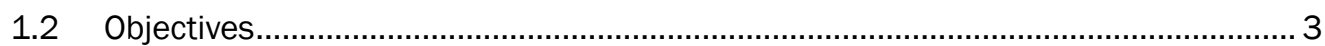

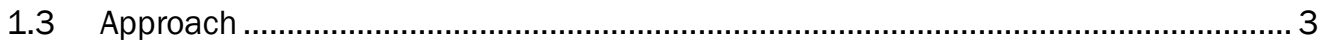
1.4 Mode of technology transfer ........................................................................ 3

2 Random Transect with Adaptive Clustering: Background...................................................... 4

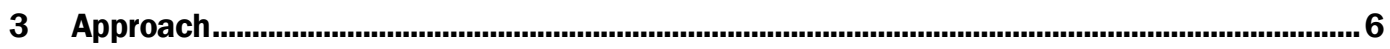

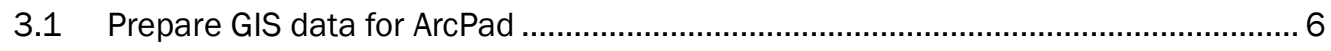

3.1.1 Create and GPS-enable the GIS sampling design geodatabase .............................. 6

3.1.2 Create features in geodatabase........................................................................... 10

3.1.3 Add additional background reference data ......................................................... 14

3.2 Check out data for ArcPad .......................................................................... 15

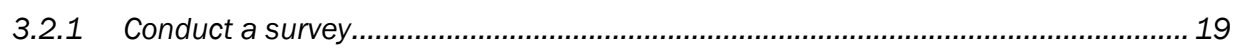

3.3 Check in data from ArcPad......................................................................... 29

References ......................................................................................................................................31

Appendix A: Requirements and Installation ..........................................................................33

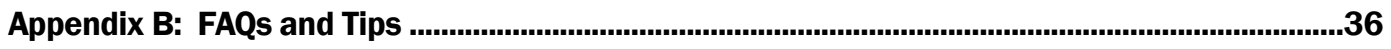

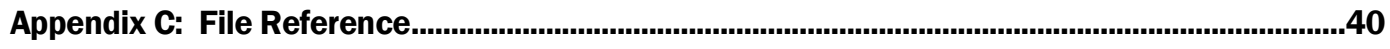

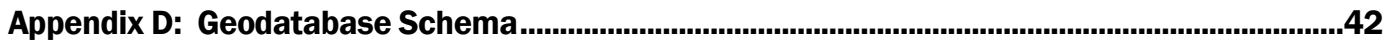

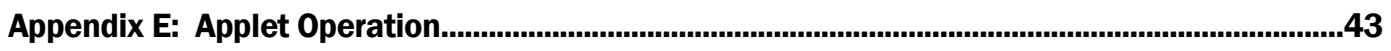

Appendix F: Applet Buttons Quick Reference.......................................................................51

Report Documentation Page 


\section{List of Figures and Table}

\section{Figures}

Figure 1. Example of a surveyGrid generated with the Survey Grid Builder tool. Brown lines represent the transect of length $79 \mathrm{~m}$, and the green squares represent cells of size $10 \mathrm{~m}$ $x 10 \mathrm{~m}$. The transect extends beyond the surveyGrid, because the length of the transect is not divisible by the cell size.

Figure 2. An example of the relationship between a surveyGrid, transect, and transect corridor feature. The orange line coming across the left side represents a road.

Figure 3. Example showing a target plant patch entirely within a maximum search and survey area. The solid black lines represent sides of the transect corridor and the dotted line the transect; blue box delineates maximum search area and pink box delineates maximum survey area. The first target species found in the transect is shown as a dark green dot, and the patch it belongs to, as captured by the GPS, is shown in lime green. Concentric rings of cells to be adaptively sampled are shown in various shades of rose. The patch crosses both sides of the transect; hence, the surveyor would adaptively sample only one side of the transect. In the illustration, the right side was assumed to be randomly chosen.

Figure 4. Example showing a target plant patch with a boundary lying outside both the maximum search and survey area. In this case, the patch is too large to carry out an adaptive sampling session. In addition, once the surveyors reach the maximum adaptive survey boundary, they would follow the survey area boundary, not the patch boundary itself, i.e., the striped patch area would not be captured with the GPS. All other lines, boxes, points, and polygons represent the same survey features as in Figure 3.

Figure 5. Example shows a target plant patch with a boundary lying outside the maximum search area but within the maximum survey area. In this case, the patch falls outside the maximum adaptive search bounding box; hence, an adaptive sampling session would not take place. Lines, boxes, points, and polygons represent the same survey features as shown in Figure 3.

Figure 6. Example showing both adaptive and transect plant features captured during an adaptive sampling session and transect sampling session, respectively.

Figure 7. Example showing transect plant points starting before and finishing after "next adaptive sampling unit” line. Survey features same as Figure 6.

\section{Table}

Table F1. Buttons on the Applet main toolbar 


\section{Preface}

This study was conducted for the Department of the Army, Office of the Director of Environmental Programs (ODEP) under Research, Development, Test \& Evaluation Program Element A896, "Base Facility Environmental Quality”; Project 030F25, “Dynamic Adaptive Inventory and Mapping of Non-Native Invasive Plants on Army Installations." The technical monitor was Steve Sekscienski.

The work was completed as part of a cooperative agreement between Montana State University and the US Army Engineer Research and Development Center - Construction Engineering Research Laboratory (ERDC-CERL). The ERDC-CERL work was performed by the Ecosystem Processes Branch ( $\mathrm{CN}-\mathrm{N})$ of the Installations Division $(\mathrm{CN})$. At that time, William Meyer was Branch Chief, CN-N; Dr. J ohn Bandy was Chief, CN; and Alan Anderson was Technical Director for Environmental Quality. The Deputy Director of ERDC-CERL was Dr. Kirankumar Topudurti and the Director was Dr. Ilker Adiguzel.

COL Kevin J. Wilson was the Commander and Executive Director of ERDC, and Dr. J effery P. Holland was the Director. 


\section{Introduction}

\subsection{Background}

It has been estimated that approximately 275,000 acres ${ }^{1}$ of Army training and testing land currently have restrictions on use that are related to nonnative invasive plant species (NIS). NIS are introduced to areas by a variety of natural and anthropogenic means. Once established, some NIS can threaten the ecological integrity of native plant communities and alter important ecosystem-level properties such as hydrology, disturbance regimes, nutrient cycling, and microbial processes (Vitousek and Walker 1989; Mack and D'Antonio 1998; D'Antonio 2000; Zavaleta 2000; Brooks et al. 2004; Ehrenfeld 2003; Bais et al. 2006; Allan et al. 2010; Hickman et al. 2010). This potential threat has made the management of NIS on federal lands, including Army training lands, mandatory by Executive Order 13112.

NIS populations can be extremely difficult and expensive to eradicate once established. A more economical and ecologically viable means of limiting NIS impacts is to prevent harmful, unwanted NIS from arriving in an area in the first place (Moody and Mack 1988; Davies and Sheley 2007). Unfortunately, NIS management strategies based on prevention have limited feasibility on Army training lands. Army land use is unique among federal land stewardship. Military operations such as off-road maneuvers, moving equipment, materiel, and personnel between sites, and driving considerable distances along unpaved roads, pose a high risk of transporting NIS propagules within and between sites. The high degree of vegetation and soil disturbance associated with training maneuvers also facilitates the establishment of NIS that are dependent on or benefit from disturbance. Limiting access to areas infested by NIS as a means of preventing unintended transport of NIS propagules is also unviable, given that training land availability does not meet established needs. Military bases do have vehicle wash stations to clean vehicles traveling within and between sites. Although this approach can reduce the number of plant propagules on a vehicle, it does not totally remove the risk of transfer. Thus, some new NIS populations are likely to establish as a result of vehicle movements. The most cost-effective and feasible strategy to address any new and recently

\footnotetext{
11 acre $=4,046.873$ square meters
} 
established NIS populations is "early detection and rapid response (EDRR)" i.e., treatment while NIS are still infrequent on the landscape (Davies and Sheley 2007). Frequently, there is lag time between introduction of NIS and the occurrence of rampant population growth and corresponding impacts (Hobbs and Humphries 1995). Treatment of small NIS populations during this lag phase can prevent widespread invasion and establishment. However, early treatment depends upon accurate detection and mapping (Dewey and Anderson 2004; Barnett et al. 2007).

Paradoxically, it is during the lag phase between introduction and rapid population growth that NIS can be the most challenging to detect and map. The large spatial size of some managed areas, coupled with limited financial resources and competing priorities, can make it impossible to conduct the complete inventory and mapping effort needed to document NIS distributions. These restraints necessitate that sampling of some type be performed. Conventional sampling designs can be inefficient and costly to implement, however, when used to sample sparsely and/ or small, patchily distributed populations that typify the early phases of NIS invasion. To increase the number of patches detected by using conventional sampling methods, sample size must be increased, but many sampling units still will not contain individuals of interest (Morrison et al. 2008).

An alternative to conventional sampling comes from adaptive cluster sampling designs that are specifically developed to take advantage of the rarity and clustered nature of many biological populations. The designs concentrate sampling effort in "hot spots" or areas with a high probability of finding the target species of interest. In general, adaptive cluster sampling designs work by first deciding upon an initial sample set. For each sample unit within the initial sample set, if the value of the variable of interest satisfies a specified condition (e.g., target species present), then neighboring units are added to the sample set. The addition of sampling units continues until the specified condition is no longer met (e.g., target species is no longer found). By concentrating sampling effort where target species are most likely to be found (i.e., near other target species), the problem of visiting unoccupied sampling units is minimized. Adaptive sampling methods can, therefore, be more efficient at detecting sparsely dispersed NIS populations when efficiency is evaluated in terms of the time spent sampling and traveling between sampling unit locations. Unfortunately, widespread field applications of adaptive cluster sampling 
designs have been limited by the availability of software and hardware tools to facilitate use by non-experts.

\subsection{Objectives}

This manual describes an adaptive cluster sampling design called the Random Transect with Adaptive Clustering (RTAC) sampling design along with a user-friendly Global Positioning System (GPS) interface developed to aid implementation of the sampling design in the field. The GPS user interface is a customized application developed for $\mathrm{ArcPad}^{\circledR}$, a mobile geographical information software (GIS) for field applications developed by ESRI ${ }^{\circledR}$ of Redlands, CA. ArcPad is designed to integrate with ESRI's desktop GIS technology, ArcGIS ${ }^{\circledR}$, and use of the application is not possible without this software. This application should be used for mapping plant species that are rare on the landscape, such as many NIS are at the early stages of invasion.

The objective of the sampling design and ArcPad application described in this manual is to assist Army land managers who want to use an EDRR NIS management strategy to detect and map the locations of NIS populations. ArcPad is fully integrated with ArcGIS and requires a geodatabase that can also become part of a longer-term NIS monitoring program to assist Army land managers in planning, budgeting, prioritizing, and tracking the effectiveness of NIS management actions.

\subsection{Approach}

Development of the RTAC sampling design is described in Chapter 2 and the user approach is described in Chapter 3.

\subsection{Mode of technology transfer}

This report will be made accessible to the public through the Engineer Research and Development Center's (ERDC's) online document repository at http://acwc.sdp.sirsi.net/client/default.

The software will be made available for download via the Montana State University, Weed and Invasive Plant Ecology and Management Group website: $\mathrm{http}$ ://weedeco.msu.montana.edu/rangewildland/index.html. 


\section{Random Transect with Adaptive Clustering: Background}

The RTAC is a combination, with slight modifications, of two sampling designs that were previously used to survey NIS. Rew and colleagues (2006) and Huebner (2007) found stratified random targeted transects to be a reliable and efficient means of surveying NIS populations. In this type of design, the person conducting the survey walks from the start to the end of each transect while recording the presence of an NIS along the way. Prather (2006) used an a second adaptive sampling design that consists of walking concentric circles around detected patches to search for additional patches. If an additional patch is detected, the process is repeated until a predefined maximum distance is reached. Sampling also stops when no more NIS are found, even if the predefined distance has not been reached.

The way in which the stratified random targeted transect and adaptive circle cluster designs are performed in the field allows information about the location of both occupied and unoccupied areas to be collected. Knowledge of areas where NIS are absent, as well as where they are present, is of considerable importance for management. The presence/ absence data are used to elucidate the potential distribution of an NIS (Prather 2006) and can be used to create probability of occurrence maps (Rew et al. 2005) to guide future surveying and management efforts.

The RTAC combines features of the two NIS sampling designs described above by having a surveyor traverse a transect from start to end, while alternating between applying an adaptive cluster sampling (referred to as an adaptive sampling session) and applying nonadaptive sampling (referred to as a transect sampling session). Patch density (stems per square meter) and patch pattern (e.g., discrete patches or individual scattered plants) data are collected at each NIS patch intersected. Similar to the previously described NIS sampling designs, both presence and absence data are collected. A customized ArcPad software application, known as an applet, was developed to guide surveyors through the RTAC while in the field.

The RTAC ArcPad application, referred to from this point forward simply as the Applet, is a user-friendly ArcPad GPS interface written in Visual 
Basic scripting language. The Applet was developed and tested for ArcPad 8.0 on a Trimble GeoXT GPS device but is designed to run on any mobile device that supports ArcPad. The Applet requires certain GIS feature classes in a geodatabase; hence, it requires ESRI ArcGIS. ${ }^{2}$ The Applet functions as a navigational GPS data collection and decision support tool to guide a user through the process of conducting a survey using the RTAC. How the Applet actually works when loaded on a GPS unit and how to prepare the ArcGIS geodatabase required by the Applet are detailed in Chapter 3.

2 This geographical information system software is available by contacting ESRI at: http://www.esri.com/software/arcgis. 


\section{Approach}

This chapter describes the process necessary for a successful field session using the RTAC Applet. It will provide a guide to the entire process, from the creation of the necessary data to the incorporation of the final sampled data into the geodatabase for monitoring and analysis. It assumes that the Applet has been correctly installed, along with all materials provided with the Applet installation files. If the Applet has not been installed yet, see Appendix A. Additionally, a summary of frequently asked questions is provided in Appendix B as a quick reference.

\subsection{Prepare GIS data for ArcPad}

This section describes how to prepare the required data for the Applet and transfer it to the GPS unit for use in the field. The process of data creation is comprised of two steps: (1) create and GPS-enable a geodatabase and (2) create features in the geodatabase's feature classes. To simplify the geodatabase creation process, an empty geodatabase schema is provided with the Applet. Also, there is a set of customized ArcGIS tools provided to help create and attribute the required features in the geodatabase. These tools are provided in the Applet installation files (also see Appendix C).

\subsubsection{Create and GPS-enable the GIS sampling design geodatabase}

The following steps show you how to prepare the geodatabase required for use with the Applet. It is assumed that you have a copy of the geodatabase schema provided with the Applet. In the event that you do not have this schema, a complete description of the geodatabase is included in chart form in Appendix D to allow you to generate a geodatabase with all necessary feature classes, fields, and attributes. To build your data with the existing schema:

\section{Step 1. Copy the schema to your working directory}

$>$ Open ArcCatalog and in the table of contents navigate to the geodatabase titled AdaptiveClusterGeodatabaseSchema.mdb you received with the Applet files.

> Copy the geodatabase to your current working directory.

$>$ This manual will use the name AdaptiveClusterGeodatabaseSchema.mdb for all examples. If you choose to rename your 
copy of the geodatabase, you will need to substitute that name in future steps, where appropriate.

> Optional - Copy this original geodatabase and store it in a safe location as a template for future use.

\section{Step 2. Define the geodatabase's spatial reference}

Each feature's spatial reference must be defined to work with ArcPad. You can choose to set the spatial reference by individual feature class or you can define it by feature dataset.

$>$ In the ArcCatalog table of contents, expand the geodatabase:

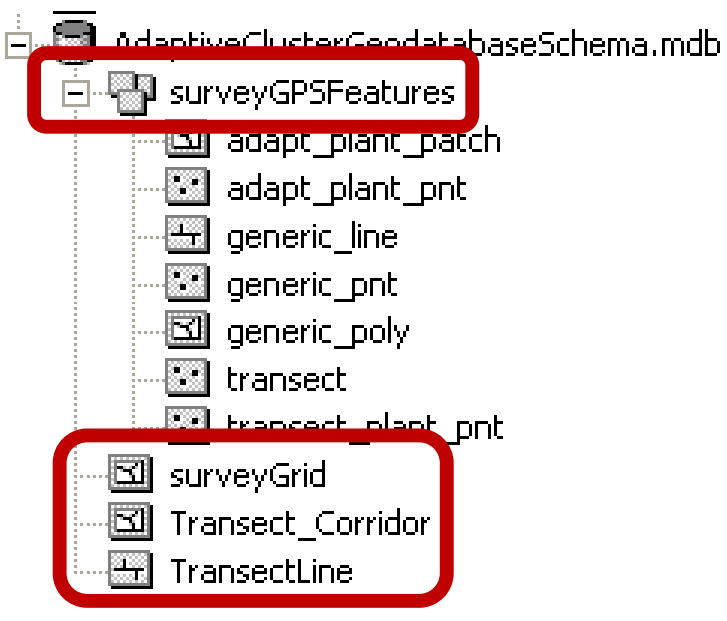

$>$ Select the feature dataset surveyGPSFeatures. Set the coordinate system by right-clicking your mouse over the dataset and selecting Properties.

$>$ Click the XY Coordinate System tab and select the coordinate system you prefer to use with your GIS data.

$>$ Click OK. This sets the spatial reference for each feature class in the feature dataset.

$>$ Repeat this process again for the feature classes

> surveyGrid, Transect_Corridor, and TransectLine.

\section{Step 3. GPS-enable the geodatabase}

GPS-enabling the geodatabase allows data to be checked out for editing in ArcPad. Note: The Trimble GPS Analyst extension must be activated in ArcMap before the geodatabase can be enabled. To enable the geodatabase, take the following steps: 
> Right click on the AdaptiveClusterGeodatabaseSchema.mdb file in the ArcCatalog table of contents and select Properties.

> Check the GPS-enable geodatabase button under the Trimble GPS Analyst tab.

> Select all of the classes that you will be updating with the GPS:

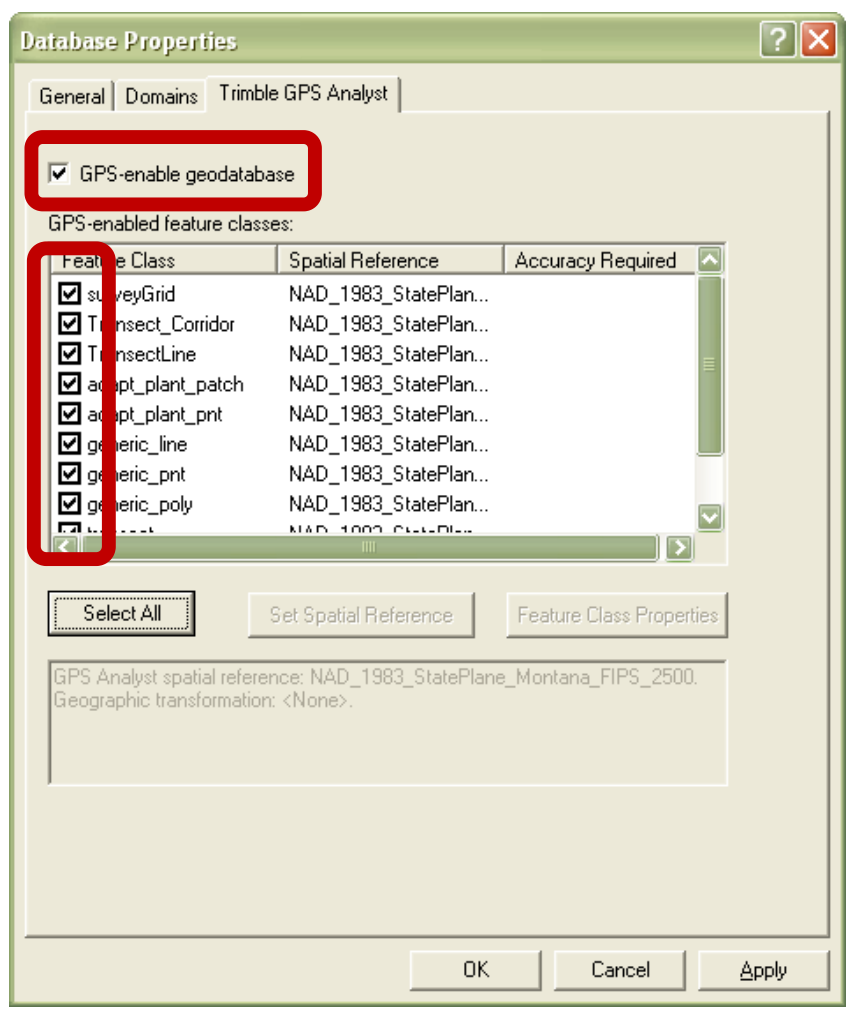

\section{$>$ Click $\mathbf{O K}$.}

> Select the appropriate transformation to convert your data from WGS 1984 into your chosen coordinate system and click $\mathbf{O K}$.

$>$ All GPS data are collected in GCS_WGS_1984. If the coordinate system that you chose to use for your geodatabase is not GCS_WGS_1984, you will need to select a transformation method so that the data from the GPS can be correctly converted from GCS_WGS_1984 to your chosen coordinate system.

$>$ ESRI provides documentation of the many transformation methods with ArcMap so that you can choose the correct transformation for your area or consult a local GIS expert. 


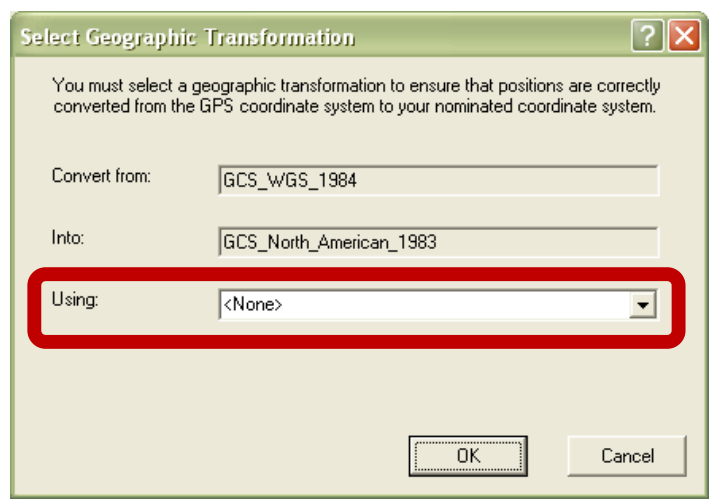

> Note: At this point, ArcCatalog may display a warning indicating that the extents of the selected feature classes are outside the extent selected while GPS-enabling the geodatabase. This occurs because the geodatabase is empty. Click $\mathbf{O K}$ to this warning. In general, this will not cause a problem. However, you can prevent possible problems in the following manner. When you start to add features to feature classes in the geodatabase, first zoom the data frame in ArcMap into a reasonable extent and scale for your intended field session. If you are unsure of the location and extent of your field sites when you first start ArcMap, load background data into ArcMap to find the correct location in the empty geodatabase.

\section{Step 4. Set GPS accuracy fields}

$>$ The geodatabase schema for the GPS feature classes includes the attribute fields ave_accuracy and worst_accuracy. These fields will record the GPS accuracies for each feature you GPScapture while in the field. By default, the geodatabase is set not to record these values in the table, hence, you need to follow these steps to activate these fields for this purpose:

$>$ In the ArcCatalog table of contents, right click on any one of the feature classes under the surveyGPSFeatures dataset.

$>$ Select Properties and click on the Trimble GPS Analyst tab.

> Use the drop down menus for Store Average Estimated Accuracy and Store Worst Estimated Accuracy to select the proper field in the geodatabase.

$>$ Click OK.

$>$ Repeat this process for each of the other feature classes under the surveyGPSFeatures dataset. 
$>$ Note: This does not need to be done for the feature classes surveyGrid and Transect_Corridor because the features in this class will only be updated rather than created.

> Your geodatabase is now GPS-enabled and ready for data preparation and check-out.

\subsubsection{Create features in geodatabase}

This Applet requires two populated feature classes to function properly, and one to aid in sample design implementation. These feature classes are TransectLine, Transect_Corridor, and surveyGrid. Tools for use in ArcMap have been provided with the Applet to simplify the creation of Transect_Corridor and surveyGrid features. A transect feature class that includes the transects to be surveyed must be provided as input to the tools prior to creating either of the remaining features classes. The transect lines themselves can be created via any process you chose, but should be created in the feature class TransectLine included in the empty geodatabase. The transect lines can be of any length, but the length should be a multiple of the cell size described below. In order for the tools to perform properly, each transect feature MUST have a unique ID.

Once the transect features in TransectLine have been created, you can use the Corridor Builder tool to generate features in the Transect_Corridor feature class and the Survey Grid Builder tool to generate features in the surveyGrid feature class. The Survey Grid Builder tool uses a transect line feature to create a set of equal area polygons, i.e., the surveyGrid (see Figure 1). The individual polygons, referred to as cells, are squares. The side lengths of these squares are referred to as cell size. For example, a cell size of $10 \mathrm{~m}$ would produce a cell for which length and width is equal to $10 \mathrm{~m}$ and area is equal to 100 $\mathrm{m}^{2}$. The Corridor Builder tool is similar to the Survey Grid Builder tool in that it creates a single, rectangular polygon corresponding to the center column of cells in the surveyGrid feature class (i.e., those cells that the transect line features bisect). The tools will build a survey grid and transect corridor corresponding to each transect feature; therefore, including several transect line features in a single TransectLine feature class will save time and effort in the construction of survey grids and transect corridor features.

Before proceeding, you should create transect line features to use with the tools. The tool will accept transects of any length. If a transect's length is 
not a multiple of the cell size; however, there will be a length of transect and corridor that extends beyond the surveyGrid. For example, if you choose a cell size of $10 \mathrm{~m}$ and a transect has length of $79 \mathrm{~m}$, there will be a $9 \mathrm{~m}$ section of the transect and corridor extending beyond the surveyGrid (see Figure 1). To avoid confusion in the field, it is best to ensure all transect lengths are multiples of cell size.

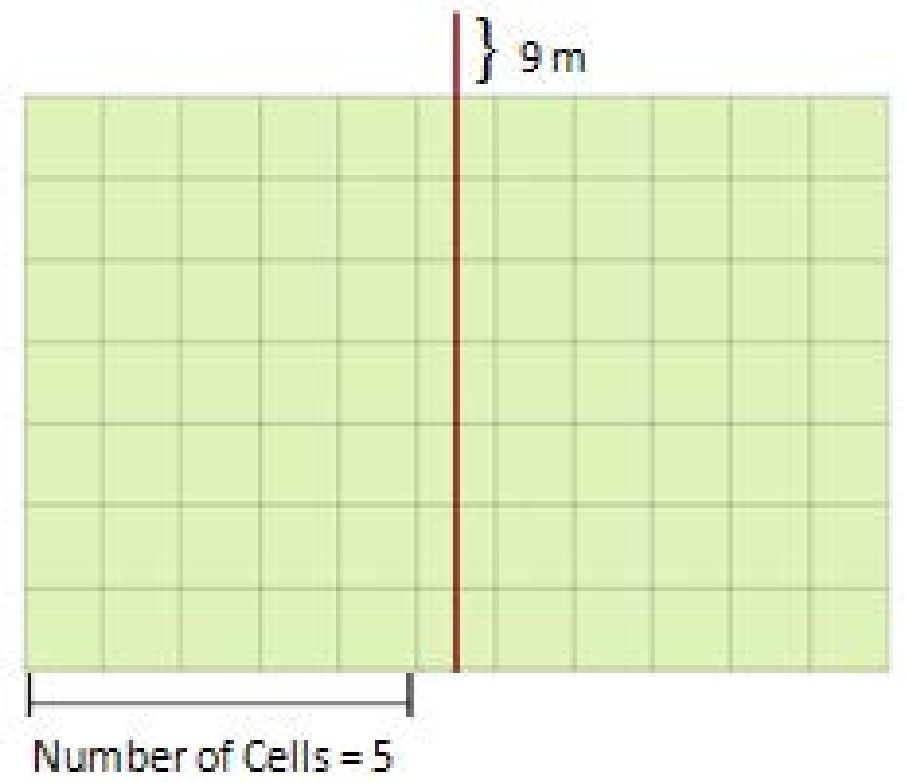

Figure 1. Example of a surveyGrid generated with the Survey Grid Builder tool. Brown lines represent the transect of length $79 \mathrm{~m}$, and the green squares represent cells of size $10 \mathrm{mx}$ $10 \mathrm{~m}$. The transect extends beyond the surveyGrid, because the length of the transect is not divisible by the cell size.

Transect features should be created in the TransectLine feature class of the geodatabase provided with the Applet. To begin creating transect features, add the AdaptiveClusterGeodatabaseSchema.mdb to an ArcMap session and create the transects in the correct feature class. If ArcCatalog brought up the warning mentioned previously when you GPS-enabled the geodatabase, ensure the transects that you created are in the correct location (by adding background data and/ or by checking the coordinates of the features). Once you have added the geodatabase to an ArcMap session and created transects, you can save the .mxd and use this map document in the following steps. 


\section{Step 1. Add the tools to ArcMap}

Locate the folder supplied with the Applet called

AdaptiveSamplingTools. This folder contains the toolbox, tools, and source scripts for each of the tools.

$>$ Optional: Copy this folder and all of its contents to a secure location for future use.

$>$ Open ArcMap.

> Right click in the ArcToolBox window and click Add Toolbox.

$>$ Navigate to the file Adaptive Sampling Tools folder provided with the Applet.

$>$ Select the Adaptive_Sampling_Tools toolbox and click Open.

The Adaptive Sampling Tools toolbox should now be added to the ArcToolBox

Step 2. Use the Survey Grid Builder tool to create the survey grids

The Survey Grid Builder tool uses the input variables Cell Size, TransectLine Feature Class, Survey Grid Feature Class, and Number of Cells to create a survey grid feature surrounding each transect line. All but the number of cells have been discussed previously.

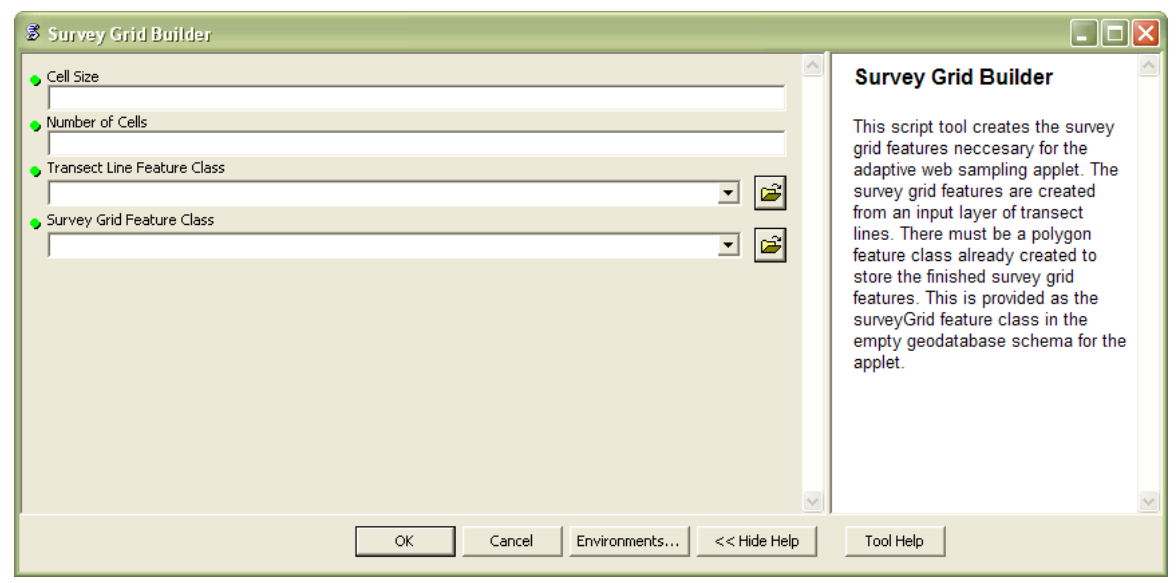

The number of cells variable defines the width of a survey grid feature; it represents the number of cells to the right or the left of the group of "center" cells that the transect line bisects (see Figure $1)$. 
A survey grid width is given by the following formula:

SurveyWidth $=(2 *($ Number of Cells $)) *($ Cell Size $)+($ Cell Size $)$

To create survey grid features in the surveyGrid feature class:

> Add the AdaptiveClusterGeodatabaseSchema.mdb to ArcMap

$>$ Create the transect line features in the TransectLine feature class if you have not already done so.

$>$ Use the geodatabase map document containing transects you have already created. If you have not created one yet, do so.

Adding the geodatabase will make the surveyGrid and TransectLine feature classes available in the drop down menus in the tool.

$>$ Double click the Survey Grid Builder script tool in the Adaptive Sampling Tools ArcToolbox.

$>$ Fill in the values for the four tool variables.

$>$ Click OK.

$>$ If you have a large number of transects or a small cell size, the tool will take several minutes or longer to build all of the survey grids.)

\section{Step 3. Use the Corridor Builder tool to create the transect corridors}

The Corridor Builder tool uses the input variables Cell Size, Transect Line Feature Class, and Corridor Feature Class to create a corridor along each transect line.

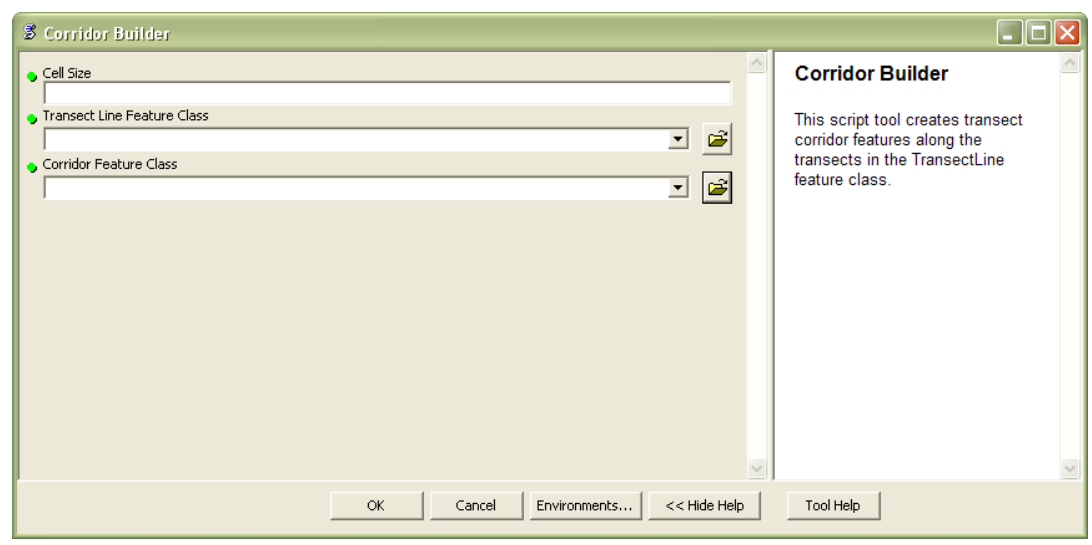


Follow these steps to create the Transect Corridor:

> Double click the Corridor Builder script tool in the Adaptive Sampling Tools ArcToolbox.

$>$ Fill in the values for the three tool variables.

$>$ Click OK.

> A finished surveyGrid, transect, and transect corridor are shown in Figure 2, along with a roads layer. The transect lines are shown in pink, the transect corridor in hatched symbology, and the surveyGrid cells in blue. Your data should look similar when finished.

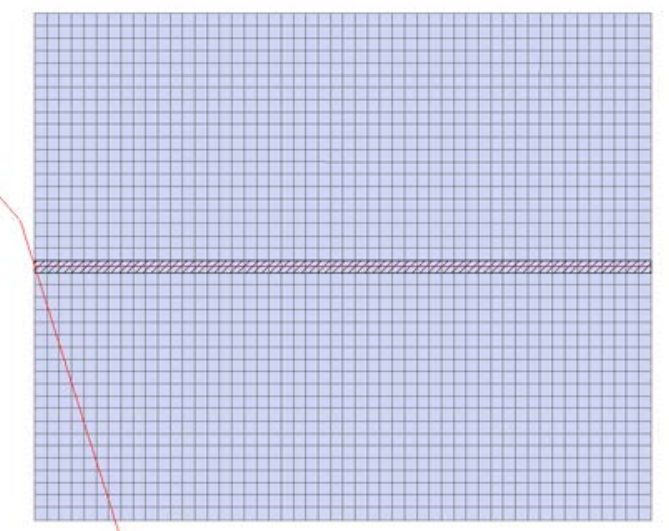

Figure 2. An example of the relationship between a surveyGrid, transect, and transect corridor feature. The orange line coming across the left side represents a road.

\subsubsection{Add additional background reference data}

Along with checking out data from the geodatabase, other GIS data can be copied out as background or reference data for use in ArcPad.

\section{Step 1. Add any background reference data needed to complete the survey.}

$>$ This could include roads, streams, or aerial photographs that will help you navigate while in the field.

\section{Step 2. Save your ArcMap document.}

> You will use this .mxd to check out and check in geodatabase layers and copy out all other layers for use in ArcMap by using the Trimble GPS Analyst. 
Once you have built and attributed all of the features required, layers in your geodatabase are ready to be checked out for use in the field.

\subsection{Check out data for ArcPad}

This section will guide you through the process of checking out data from your GPS-enabled geodatabase and transferring it to a GPS device for use in the field. Here, you will check out all of the feature classes required by the Applet to function, as well as any layers useful for navigation or reference as background layers. This manual assumes that you have the proper program files for installation of the Applet on your GPS unit and that the Applet is correctly installed on the unit. If the Applet is not currently installed on your GPS unit see Appendix B.

\section{Step 1. Get the appropriate buttons.}

Before beginning the data check-out process, ensure that the correct buttons are present on the Trimble GPS Analyst toolbar. The buttons required for this process are (1) Get Data for ArcPad and (2) Check in ArcPad Shapefiles and GPScorrect SSF.

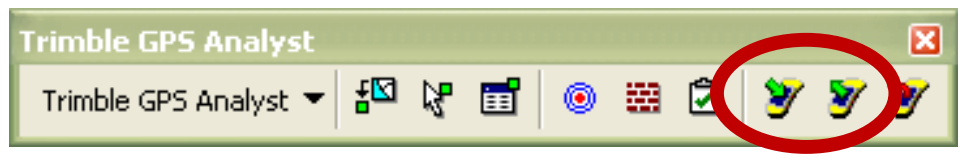

If you do not find the buttons on the toolbar they must be added before beginning data check-out. To do this:

$>$ Right click on the Trimble GPS Analyst toolbar.

$>$ Scroll through the list and click on Customize.

$>$ Select the Commands tab.

> Under the Categories heading select Trimble GPS Analyst.

$>$ Select the tools under the Commands heading and drag them onto the Trimble GPS Analyst toolbar.

$>$ The Check-in ArcPad button will be grey and unavailable on the toolbar until data have been checked out and a GPS Editing session has been started.

$>$ To avoid confusion, unnecessary buttons can be dragged off the toolbar if they are not needed.

$>$ When you have added the necessary buttons, click Close. 


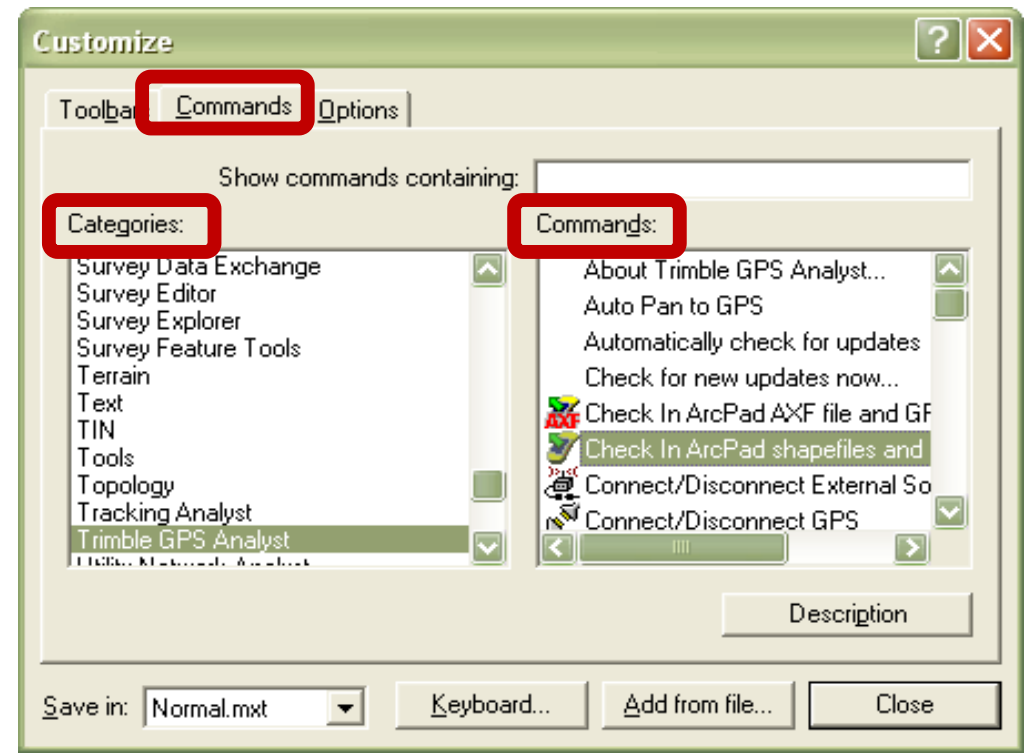

\section{Step 2. Connect the GPS unit to the computer using Ac-} tiveSync.

$>$ Connect using the method you are accustomed to.

$>$ A Guest Partnership is the recommended connection method.

\section{Step 3. Check out data.}

$>$ Open the ArcMap .mxd containing your geodatabase that you saved in Step 2 of Section 3.1.3

$>$ Zoom to the extent of the data you wish to check out.

$>$ It is strongly recommended that you set the extent to a single survey grid feature and check out only one survey grid per check-out session. By doing so, ArcPad will run much faster. ArcGIS allows multiple check-outs from a geodatabase and you can load multiple check-out sessions on your GPS units to use in ArcPad at one time. Hence, if you have several survey grid features in your surveyGrid class and check them out separately, it will not cause any problems in either ArcPad or your geodatabase.

> It may be helpful to create a bookmark at each survey grid for future reference or check-out.

$>$ Click the Get Data icon to access the menu for data selection:

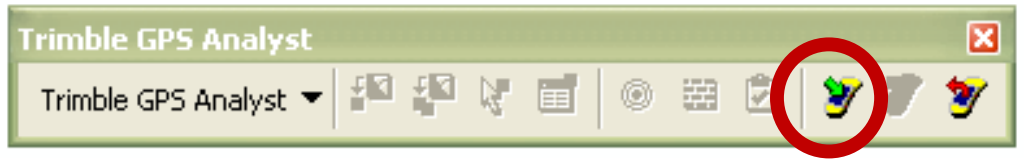


Select all the layers that you wish to display in ArcPad including background files and click Next.

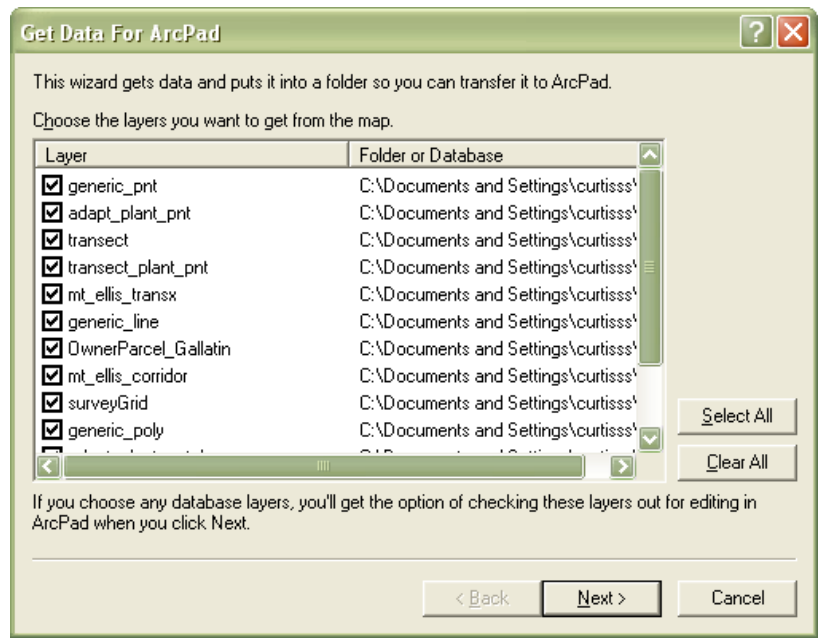

Select all the layers to check out for GPS editing in ArcPad and click Next.

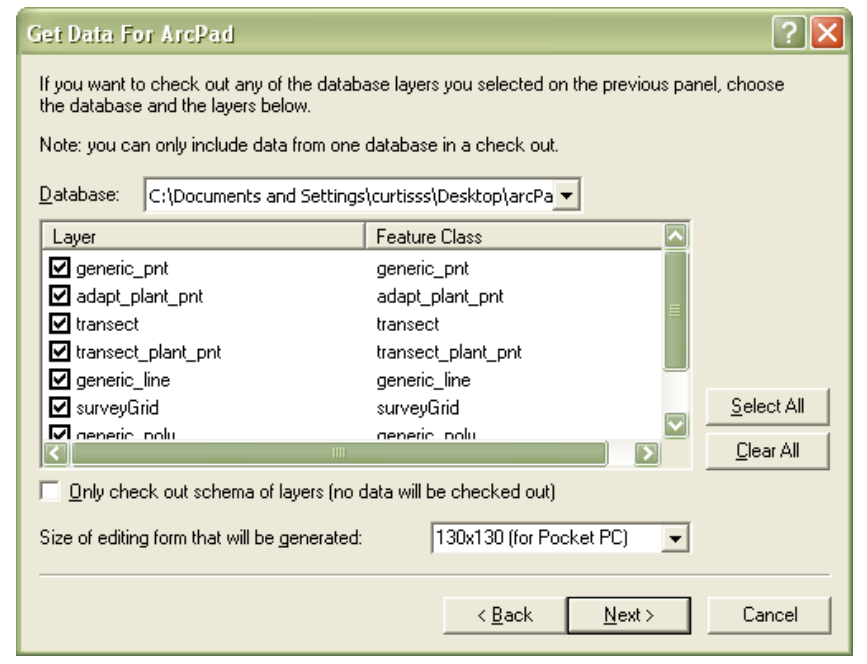

$>$ Verify that the radio button next to The Current Display Extent is selected. This button is located under the question What spatial extent do you want to get data for?

This limits the amount of information that will be transferred onto the GPS unit.

$>$ Specify a name and a location on your desktop to save the checked-out data.

$>$ Verify that the Create an ArcPad map checkbox is selected.

$>$ Click Finish. 


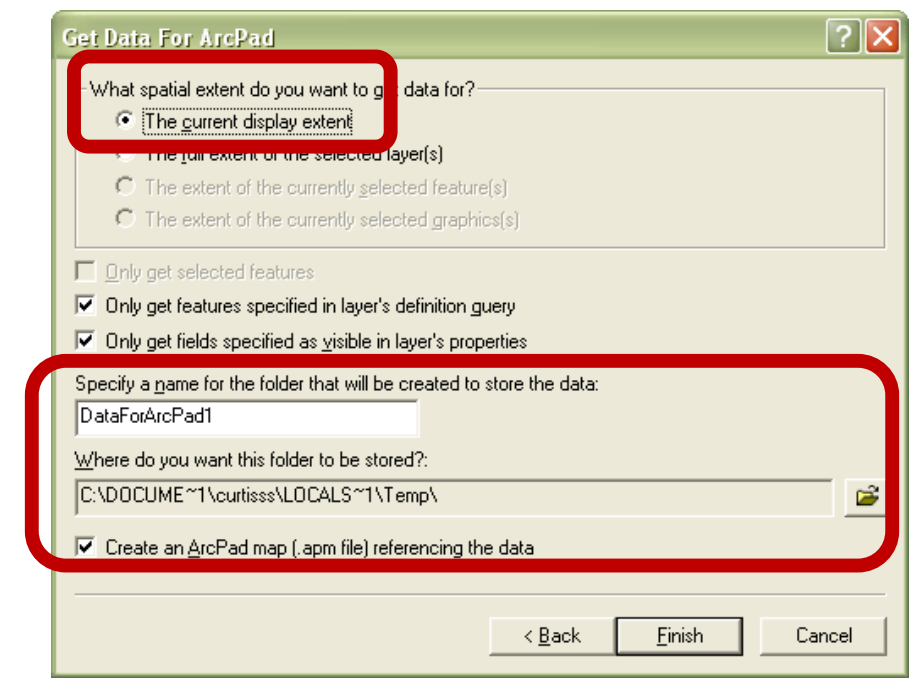

\section{Step 4. Transfer checked out data to the GPS unit.}

$>$ Open the folder you specified during the check out process to have your data placed.

$>$ Rename the ArcPad .apm file to a more descriptive name.

$>$ Delete the .sbn and .sbx file extensions from the surveyGrid files.

> The above step allows ArcPad to run much faster and is strongly recommended.

$>$ Do not delete these files for any other layers; only the surveyGrid.

$>$ Choose a location on the GPS unit and copy the data folder to the GPS using Copy and Paste.

$>$ It is recommended to copy your data to the Mobile Device Screen of your GPS unit or to the default path used by ArcPad.

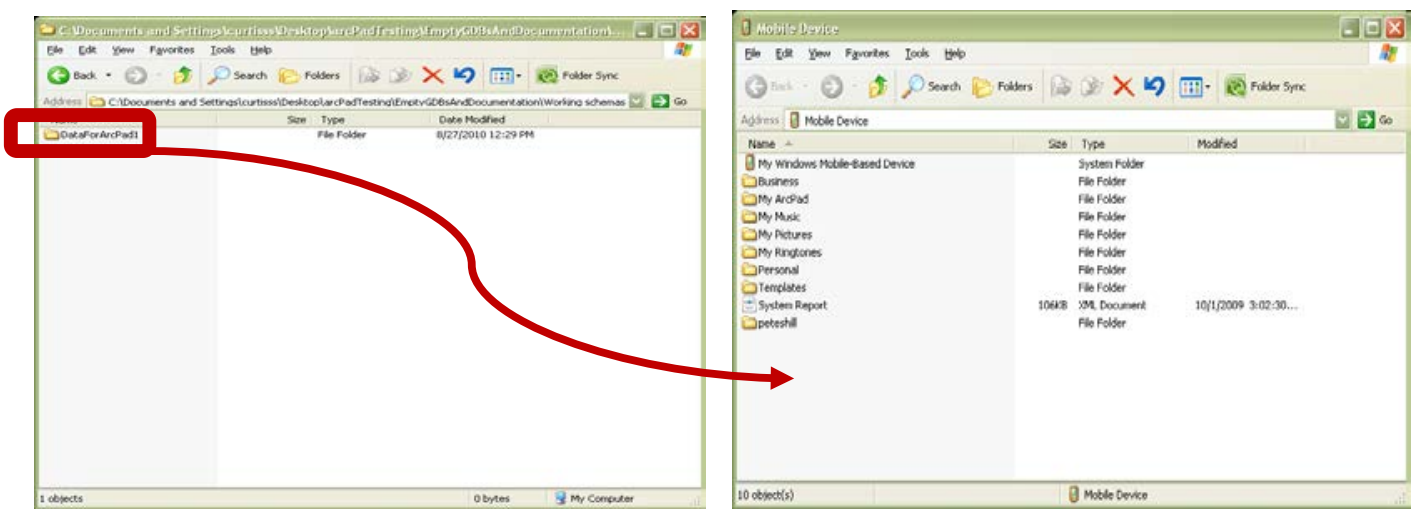




\section{Step 5. Customize the .config file.}

Before going into the field, you will want to customize the Applet's configuration file, AdaptiveSampling.config. The configuration file sets variables required by the Applet to the appropriate layer names in the user's geodatabase and specifies possible values for certain fields, such as targeted species or surveyor names. Specified values for these fields will show up in the form of pick lists when the Applet is used. While still connected to the GPS unit with active sync:

> Use Windows Explorer to navigate to the folder in the Mobile Device window that contains the Applet files.

$>$ Copy the AdaptiveSampling.config file onto your computer and update the necessary fields.

> Fill in all pick lists with the desired possible values.

$>$ Verify that the layers that were checked out from the geodatabase are properly specified in the

AdaptiveSampling.config file and update the file names as necessary.

$>$ If the feature class layer names in the

AdaptiveSampling.config file for the variables are not the same as the feature class layer names that were checked out from the geodatabase, the Applet will not function correctly. For example, by default the TransectLineLayer $=$ TransectLine . If, however, the transect line layer named in your geodatabase was, for example, "Transx" in the geodatabase, then the variable TransectLineLayer should be set equal to Transx.

$>$ If you used the schemas provided to create your geodatabase, no variables relating to the geodatabase should need to be changed. See Appendix D for more information.

$>$ Verify that the drawmaxsurveyarea field is set to true.

$>$ Replace the AdaptiveSampling.config file in the Applet file with the updated file.

\subsubsection{Conduct a survey}

After you have checked out and transferred your data to your GPS unit, start ArcPad and make sure you can open the .apm file. For the field work, you will want to take along a few small flags to stick in the ground at your site; these have been found useful to mark patch boundaries and plant locations. 
This section will guide you through the process of carrying out a survey using the RTAC Applet described above. You may also want to consult Appendices $\mathrm{E}$ and $\mathrm{F}$ for additional details and explanatory graphics. The following steps assume that you have opened the appropriate ArcPad map (.apm) containing the GIS data for data collection or update, activated the GPS receiver, and verified the GPS status.

In general, you will traverse a transect from beginning to end while looking for the target plant species within the transect corridor. Once a target species is found, you will capture either a transect plant point feature or an adaptive plant point or patch feature, depending on whether or not you are currently in an adaptive sampling section of the transect. If you capture an adaptive plant feature, you will then begin implementing adaptive cluster sampling (i.e., walking in concentric circles centered at the adaptive plant feature looking for neighboring target species). In the Applet, the concentric circles consist of rings of cells. The specific process is presented as a series of steps below. The steps assume you will be starting with adaptive sampling, but you can start with either adaptive or nonadaptive transect sampling. Also, the terms "target plant species," "target species," and "plant" are used interchangeably, as the only plants of concern are the target plant species.

Step 1. Move to the transect start and record a start point using the Capture Transect Point button.

$>$ Enter or choose values for TransectID, Point Type, Target Species, Surveyor1, Surveyor2, Maximum Search Distance, and Maximum Survey Distance.

\section{Step 2. Move from cell to cell by following the transect while looking for the target species within the transect corridor.}

$>$ If the target species is not found within a cell, use the Update Current Grid Cell button to update its sampled status to Sampled Absent.

$>$ Once a target species is found, look around to see if another plant(s) is within $10 \mathrm{~m}$ of the current plant.

> If no additional plants are detected or if the plant patch is too small to be captured by the GPS as a polygon, use the Capture Adaptive Plant Point button to capture the plant feature. 
> If additional plants are found, then use the Capture Adaptive Plant Patch button to capture the patch as a polygon feature.

- When you click on the Capture Adaptive Plant

Patch button, the maximum adaptive survey area and maximum adaptive search area will be delineated by the GPS unit and shown on the screen (see Figure 3).

Only move along the patch perimeter that lies within the maximum survey area.

- Should the patch perimeter extend beyond the maximum survey area boundary, when you reach the maximum survey area boundary, just follow its boundary until it intersects the patch perimeter again (see Figure $4)$.

- Should the patch perimeter extend beyond the maximum search area boundary, the actual patch perimeter should be mapped (see Figure 5).

\section{Step 3. Enter values once plant feature has been captured.}

> Once the plant feature has been captured, enter values (in the dialog box that appears) in the appropriate fields for plant density, percent cover, and spatial pattern of individual plants within the patch. Click OK.

$>$ The Applet will display the cells to be adaptively sampled. The cells to be sampled adaptively should be thought of as sets of concentric "rings" of cells formed around the patch. The cells immediately adjacent to the patch form the first ring; the cells immediately adjacent to the first ring of cells form the second ring; and so forth. The number of rings in the set corresponds to maximum search area divided by the cell size (see Figure 3).

$>$ If the patch perimeter extends beyond the maximum search area, no adaptive sampling will take place for this patch because of the patch's large size. Click the Clear Max Survey Area button, which actually clears the maximum search and survey areas, as well as the cells to be adaptively sampled. Go back to Step 2. 
Step 4. Begin an adaptive sampling session if the plant patch boundary falls within the maximum search area.

$>$ If the patch intersects the transect centerline, only cells on the right or left side of the transect should be adaptively sampled. Whether the right or left side of the transect is sampled is determined randomly by the Applet by pressing the Coin Toss button, which will randomly indicate Right/Clockwise or

\section{Left/Counterclockwise.}

$>$ Begin adaptive sampling by using the Coin Toss button to determine whether to start circling the plant patch in a clockwise or counter clockwise direction. Start walking around the patch in the selected direction, stopping in each cell in the first ring of cells looking for more target species. If the target species is not found within a cell, use the Update Current Grid Cell button to update its sampled status to Sampled Absent. If no target species are located in the first ring, begin walking the second ring of cells, but in the opposite direction.

$>$ Continue moving around the patch alternating between clockwise and counter-clockwise directions until all cells the Applet has displayed are sampled (i.e., the adaptive sampling session is complete).

- If a target species is found at any time while circling, go back to Step 2.

- Note: Once a new patch or plant is located, the grid cells selected in Step 3 for the previous patch or plant and not yet sampled are not traversed, and those grid cells that the Applet updated as Need to Sample are set back to Not Sampled and displayed accordingly. 


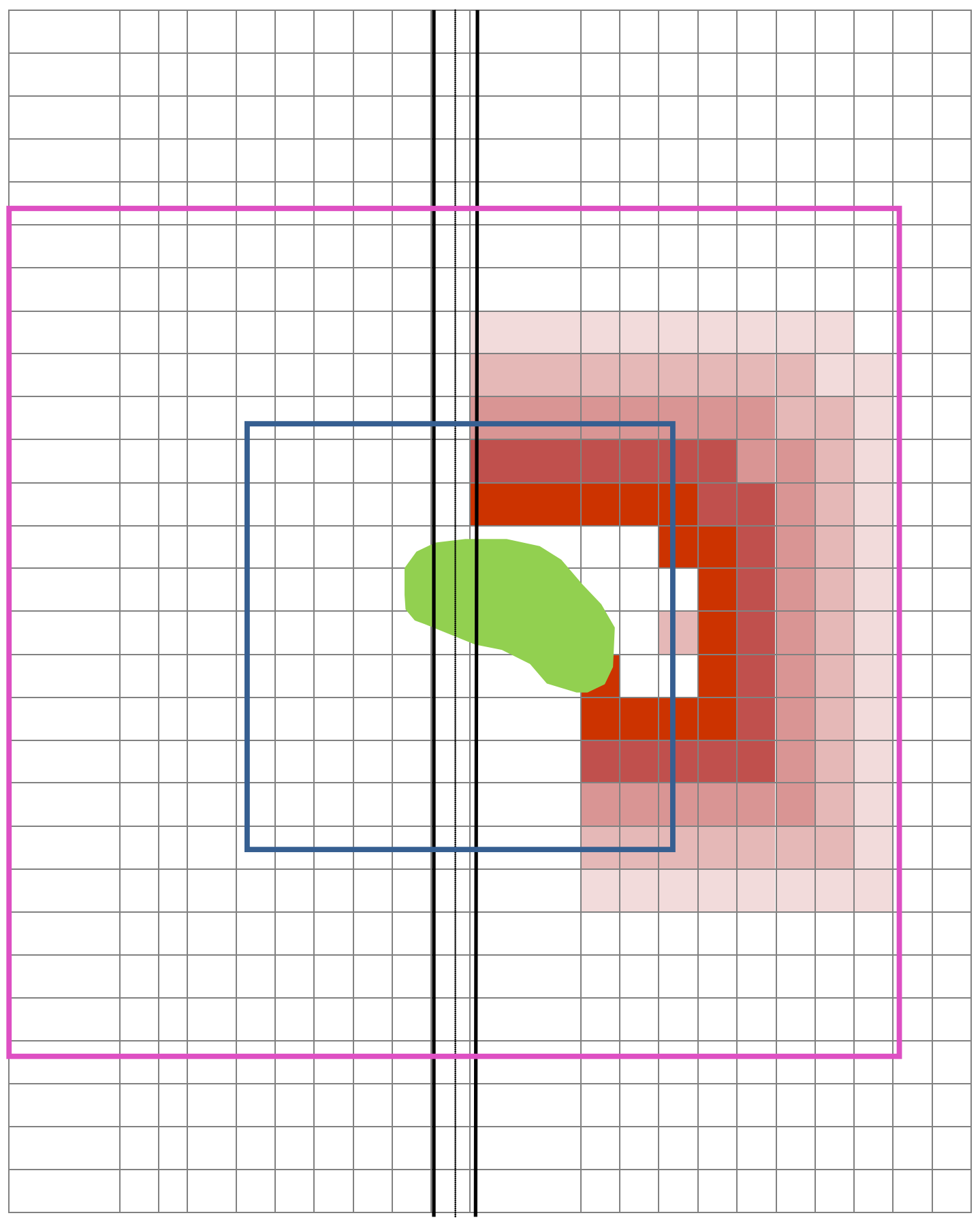

Figure 3. Example showing a target plant patch entirely within a maximum search and survey area. The solid black lines represent sides of the transect corridor and the dotted line the transect; blue box delineates maximum search area and pink box delineates maximum survey area. The first target species found in the transect is shown as a dark green dot, and the patch it belongs to, as captured by the GPS, is shown in lime green. Concentric rings of cells to be adaptively sampled are shown in various shades of rose. The patch crosses both sides of the transect; hence, the surveyor would adaptively sample only one side of the transect. In the illustration, the right side was assumed to be randomly chosen. 


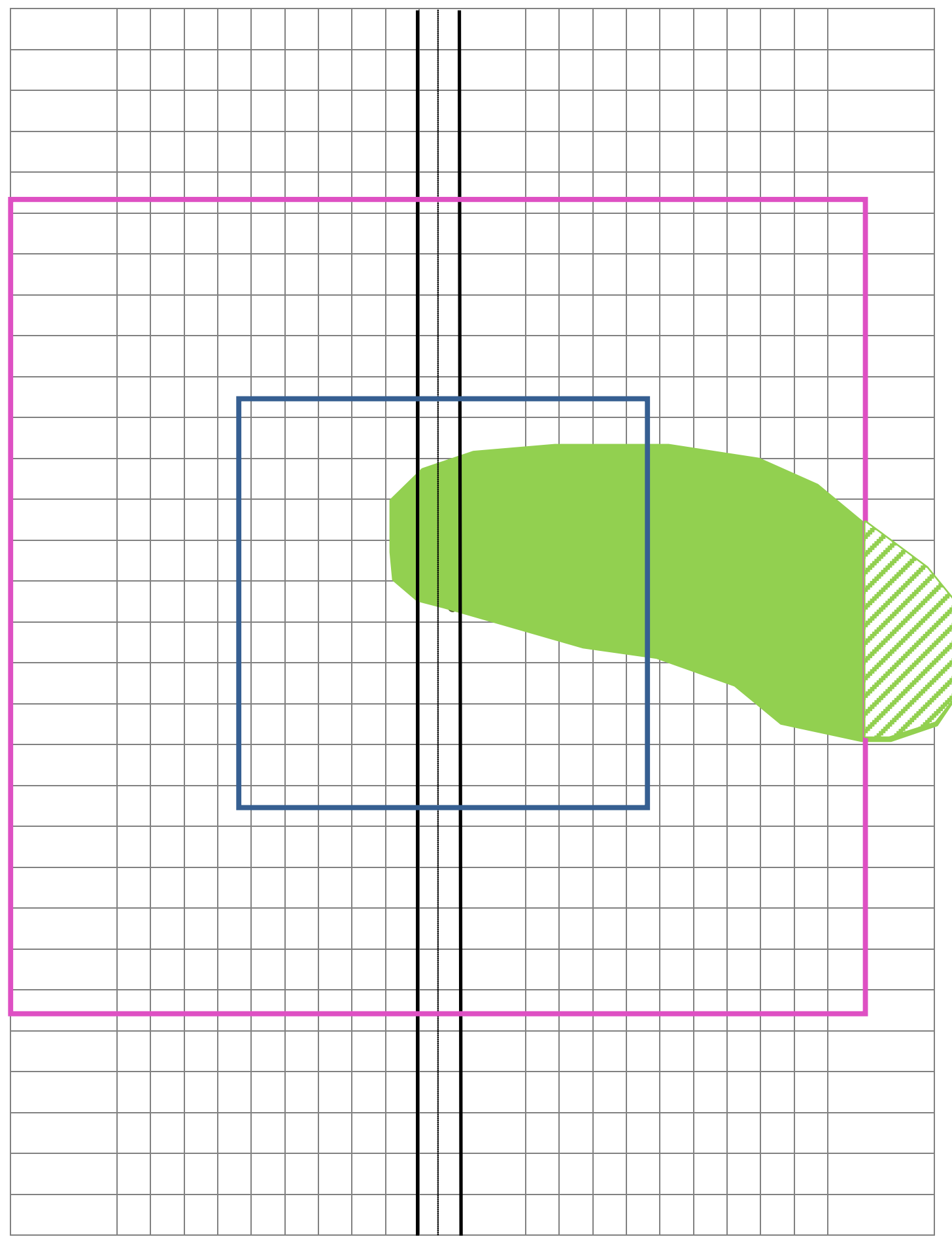

Figure 4. Example showing a target plant patch with a boundary lying outside both the maximum search and survey area. In this case, the patch is too large to carry out an adaptive sampling session. In addition, once the surveyors reach the maximum adaptive survey boundary, they would follow the survey area boundary, not the patch boundary itself, i.e., the striped patch area would not be captured with the GPS. All other lines, boxes, points, and polygons represent the same survey features as in Figure 3. 


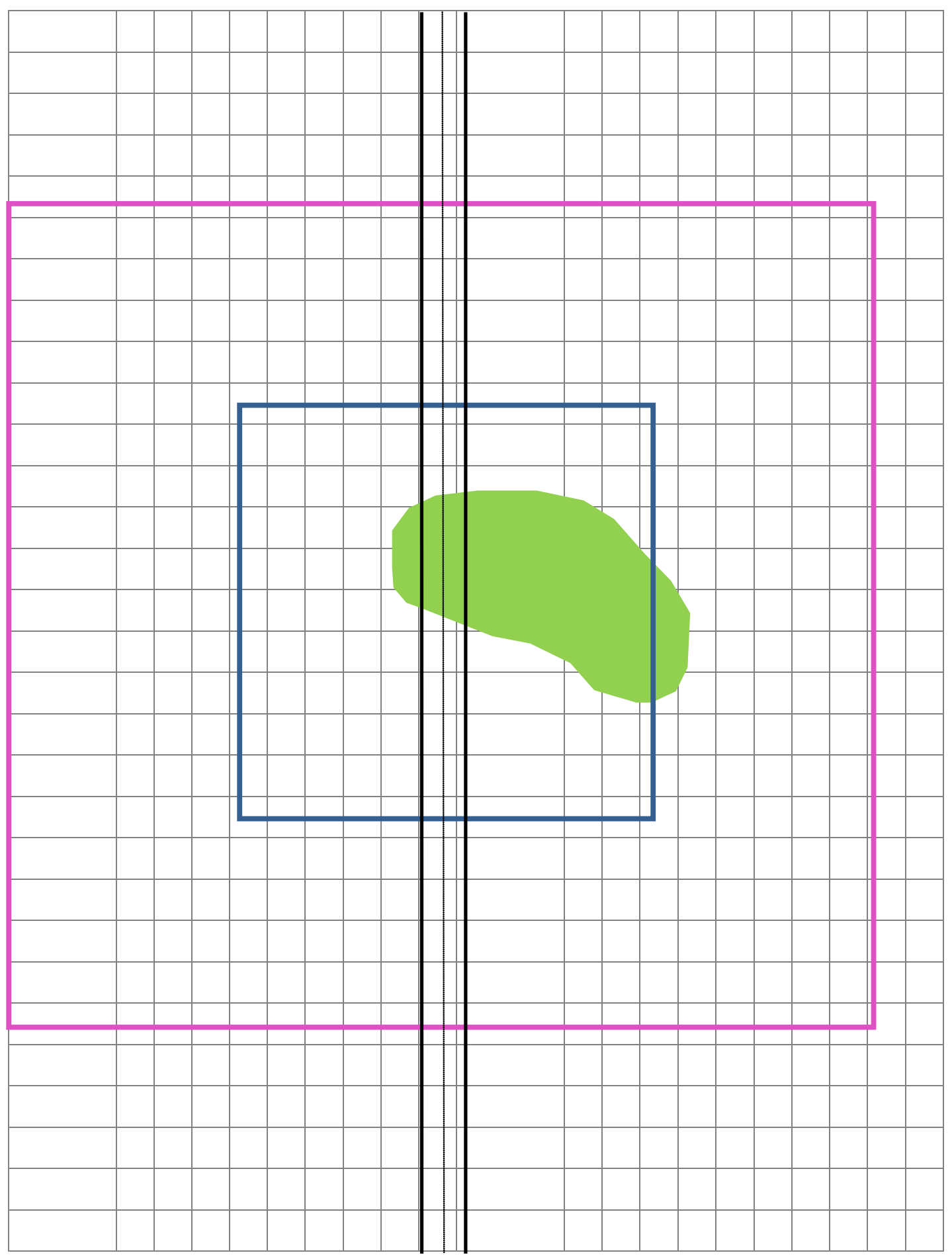

Figure 5. Example shows a target plant patch with a boundary lying outside the maximum search area but within the maximum survey area. In this case, the patch falls outside the maximum adaptive search bounding box; hence, an adaptive sampling session would not take place. Lines, boxes, points, and polygons represent the same survey features as shown in Figure 3. 
Step 5. Once the adaptive sampling session is complete, click the Clear Max Survey Area button.

$>$ This action actually clears the maximum search and survey areas, as well as the cells to be adaptively sampled.

$>$ Move back to the transect corridor and move to the next grid cell along the transect corridor that has not yet been sampled.

$>$ The Draw Next Adaptive Search Unit button should be pressed and an " $\mathrm{X}$ " indicating where the next adaptive sampling session can take place will appear (see Figure 6).

\section{Step 6. Continue down the transect.}

$>$ If a target plant is found before reaching the " $\mathrm{X}$ " that demarcates the next adaptive area, it should be mapped as a transect plant point rather than an adaptive plant point, and should not be adaptively sampled. A transect plant point will have the same attributes as an adaptive plant patch but will be managed as a separate feature class, so that it can be identified separately in the geodatabase. In addition, a transect plant point has a position attribute field that can have one of the following values: Start, End, or Middle (see Figure 6).

$>$ If a target plant is found after reaching the " $\mathrm{X}$ " that demarcates the beginning of the next adaptive sampling session, go to Step 2 (see Figure 7).

$>$ If a transect plant point starts before the " $\mathrm{X}$ " that demarcates the next adaptive sampling set but finishes after the $\mathrm{X}$, an adaptive sampling session is not carried out. One will be carried out, however, on the next target species found, if any (see Figure 7).

\section{Step 7. Move to the transect end and record a transect end point using the GPS.}




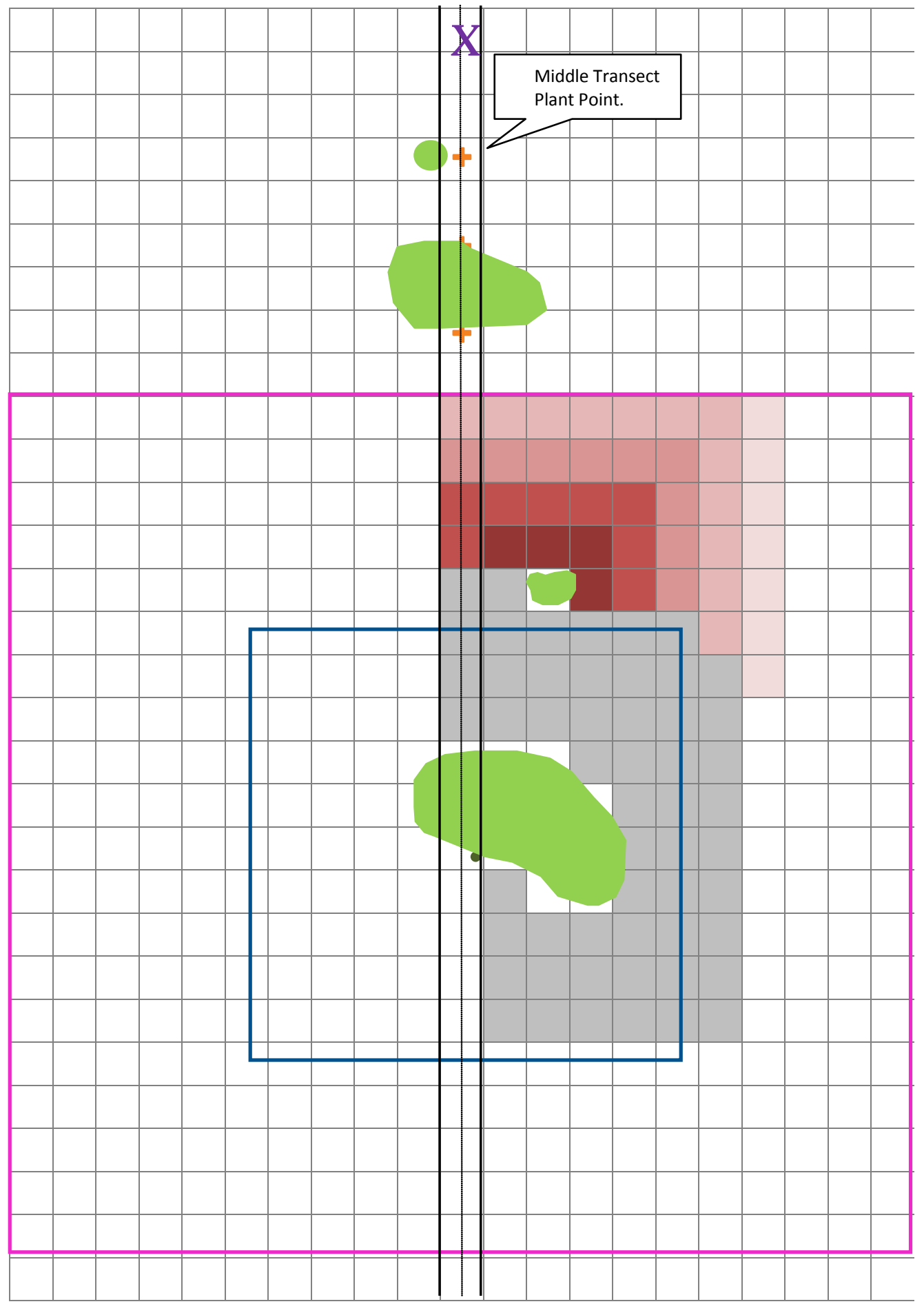

NOTE: Gray cells represent cells sampled adaptively relative to the first patch location and where no target species were found. The set of orange cells represent the concentric rings of cells that were surveyed relative to the second patch detected while surveying the cells associated with the first patch. The first transect plant patch is delineated by a start point and an end point. The second transect plant patch is captured using a single Middle Transect Plant Point. The purple $\times$ indicates the location along the transect where the next adaptive sampling session could take place should another target species be detected. Lines, boxes, points, and polygons represent the same survey features shown in Figure 3.

Figure 6. Example showing both adaptive and transect plant features captured during an adaptive sampling session and transect sampling session, respectively. 


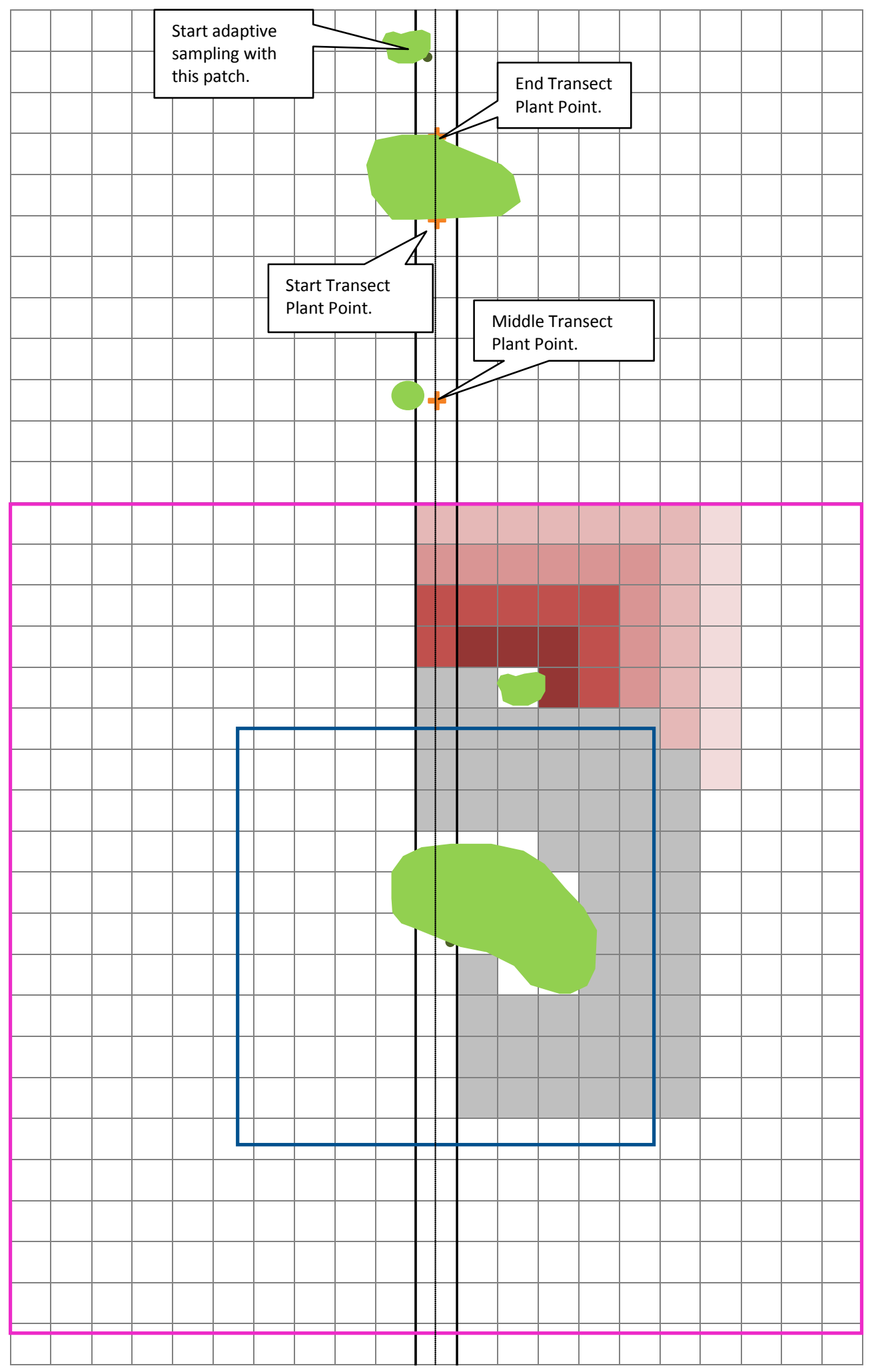

Figure 7. Example showing transect plant points starting before and finishing after "next adaptive sampling unit" line. Survey features same as Figure 6. 


\subsection{Check in data from ArcPad}

After completing a successful field session, it is necessary to check your survey data back into the geodatabase. This section will guide you through the process of data check-in. Once your data are successfully checked in, they are ready for post-processing and then further analysis or other final use. Note: Data check-in and check-out transactions are both PC-specific; this means that you must use the same computer to both check out and check in the data.

\section{Step 1. Connect the GPS unit to the computer using ActiveSync}

$>$ Connect using the method you are accustomed to.

$>$ A Guest Partnership is the recommended connection method.

\section{Step 2. Check in data}

$>$ Transfer the data folder from the GPS back to the computer using Windows Explorer.

You want to replace the file that was originally checked out with the new updated file. By replacing the original folder, the Trimble GPS Analyst will know where to find your updated information.

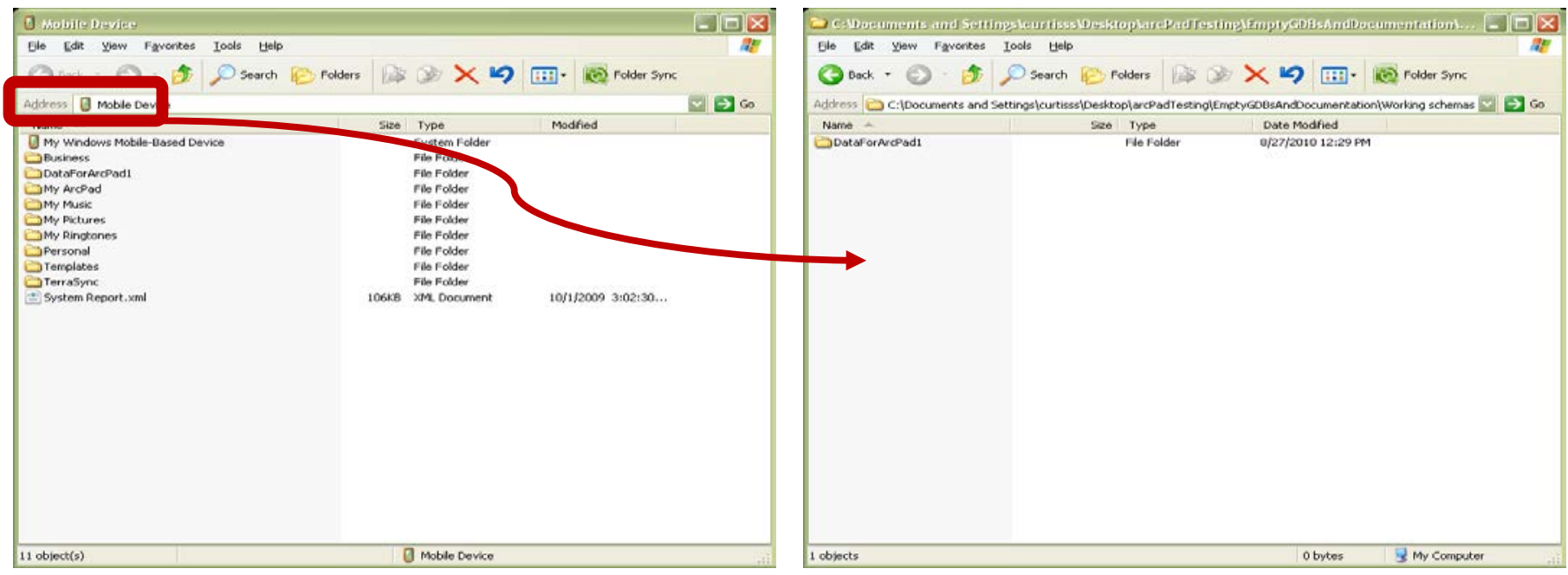


$>$ Open ArcMap and the map document (.mxd) containing your geodatabase.

$>$ Start a GPS edit session by select Start GPS Editing under the Trimble GPS Analyst toolbar.

> This will simultaneously start an ArcMap edit session.

$>$ This also activates the Check in ArcPad shapefiles and GPS correct SSF button.

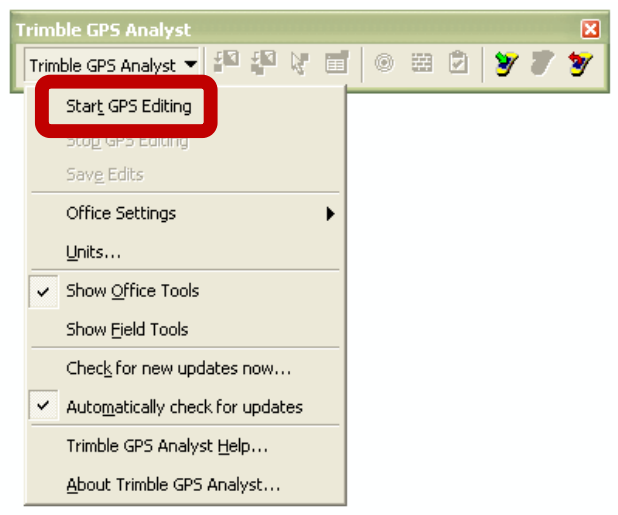

> Use the Check In Data button to select the layers that need to be checked in to your geodatabase. Select all the layers that you checked out for editing.

$>$ Click OK to begin the import process.

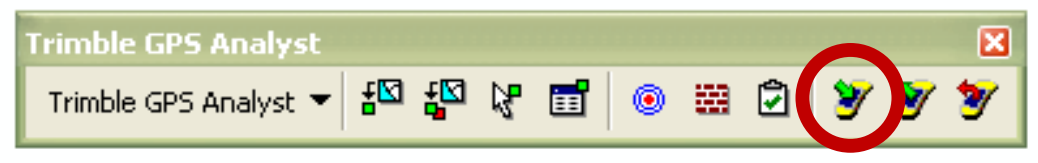

Once the import is finished, you are ready to post-process your data using the Trimble GPS Analyst toolbar. 


\section{References}

Allan, B. F., H. P. Dutra, L. S. Goessling, K. Barnett, J . M. Chase, R. J . Marquis, G. Pang, G. A. Storch, R. E. Thach, and J . L. Orrock. 2010. Invasive honeysuckle eradication reduces tick-borne disease risk by altering host dynamics. Proceedings of the National Academy of Sciences of the United States of America 107(43):18523- 18527.

Bais, H. P., T. L. Weir, L. G. Perry, S. Gilroy, and J . M. Vivanco. 2006. The role of root exudates in rhizosphere interactions with plants and other organisms. Annual Review of Plant Biology 57:233-266.

Barnett, D. T., T. J . Stohlgren, C. S. J arnevich, G. W. Chong, J . A. Ericson, T. R. Davern, and S. E. Simonson. 2007. The art and science of weed mapping. Environmental Monitoring and Assessment 132:235- 252.

Brooks, M. L., C. M. D'Antonio, D. M. Richardson, J . B. Grace, J . E. Keeley, J . M. DiTomaso, R. J . Hobbs, M. Pellant and D. Pyke. 2004. Effects of invasive alien plants on fire regimes. BioScience 54(7):677- 689.

Davies, K. W., and R. L. Sheley. 2007. A conceptual framework for preventing the spatial dispersal of invasive plants. Weed Science 55(2):178- 184.

Dewey, S. A., and K. A. Anderson. 2004. Distinct roles of surveys, inventories, and monitoring in adaptive weed management. Weed Technology 18:1449- 1452.

D’Antonio, C. M. 2000. Fire, plant invasions and global change. In Invasive Species in a Changing World. (ed. H. A. Mooney and R. J . Hobbs) pp 65-93. Washington, DC: Island Press.

Ehrenfeld, J . G. 2003. Effects of exotic plant invasions on soil nutrient cycling processes. Ecosystems 6:503- 523.

Hickman, J ., S. Wu, L. J . Mickley, and M. T. Lerdau. 2010. Kudzu (Pueraria montana) invasion doubles emissions of nitric oxide and increases ozone pollution. Proceedings of the National Academy of Sciences of the United States of America 107(22):10115- 10119.

Hobbs, R. J ., and S. E. Humphries. 1995. An integrated approach to the ecology and management of plant invasions. Conservation Biology 9:761- 770.

Huebner, C. 2007. Detection and monitoring of invasive exotic plants: a comparison of four sampling methods. Northeastern Naturalist 14:183- 206.

Mack, M. C., and C. M. D’Antonio. 1998. Impacts of biological invasions on disturbance regimes. Trends in Ecology and Evolution 13:195- 198.

Moody, M. E., and R. N. Mack. 1988. Controlling the spread of plant invasions: the importance of nascent foci. J ournal of Applied Ecology 25:1009- 1021. 
Morrison, L. W., D. R. Smith, C. C. Young, and D. W. Nichols. 2008. Evaluating sampling designs by computer simulation: a case study with the Missouri bladderpod. Population Ecology 50:417- 425.

Prather, T. S. 2006. Adaptive sampling design. Inventory and survey methods for nonindigenous plant species. L. J . Rew and M. L. Pokorny (eds.). Montana State University Extension:56- 59.

Rew, L. J., B. Maxwell, F. L. Dougher, and R. Aspinall. 2006. Searching for a needle in a haystack: evaluating survey methods for non-indigenous plant species. Biological Invasions 8:523- 539.

Rew, L. J., B. D. Maxwell, and R. Aspinall. 2005. Predicting the occurrence of nonindigenous species using environmental and remotely sensed data. Weed Science 53:236- 241.

Vitousek, P. M., and L. R. Walker. 1989. Biological invasion by Myrica Faya in Hawaiiplant demography, nitrogen-fixation, ecosystem effects. Ecological Monographs. 59:247- 265.

Zavaleta, E. 2000. The economic value of controlling an invasive shrub. Ambio. 29:462467. 


\title{
Appendix A: Requirements and Installation
}

\section{Operating system and GPS unit}

- ArcPad 7.1 or greater

- GPS unit with Windows Mobile 6 or greater installed

This Applet was tested on and is recommended for use with Trimble GPS units.

\section{Configuration file}

There is a configuration file supplied with the Applet called AdaptiveSampling.config. This is a customization file for the Applet that stores information required by the Applet and can be edited in a text editor before being uploaded to the device. An example configuration file follows. Variables in bold are required values.

\author{
Surveyor 1=Bruce,Leroy,J oe,Ted,J eff \\ Surveyor2=Bruce,Leroy,J oe,Ted,J ack \\ dalmatica, Phleum pratense, \\ MaximumSearchDistance $=50$ \\ MaximumSurveyDistance $=100$ \\ IntervalDistance $=10$ \\ PlantPatchLayer $=$ adapt_plant_patch \\ PatchPointLayer=adapt_plant_pnt \\ PlantPointLayer=transect_plant_pnt \\ GridLayer $=$ surveyGrid \\ TransectLineLayer $=$ TransectLine \\ TransectIDField=TransectID \\ TransectPointLayer $=$ transect \\ CurrentSurveyor1=Leroy \\ CurrentSurveyor2=Ted
}

TargetSpecies=Bromus tectorum, Cirsium arvense, Cynoglossum officinalis, Linaria 
CurrentTransectID $=55$

CurrentTargetSpecies=Cirsium arvense

drawnmaxsurveyarea=false

The variables TransectLineLayer, TransectPointLayer, PlantPatchLayer, PatchPointLayer, PlantPointLayer, and GridLayer refer to the layers in the geodatabase that were checked out for use with the Applet. If you have renamed the feature class layers prior to checkout, you will have to modify the names here so that the Applet knows which layers to use for each variable. For example, using the above list, the Applet will look for a TransectLineLayer named TransectLine. If, however, the transect line layer name was changed to, for example, Transx in the geodatabase, then the variable TransectLineLayer should be set to TransectLineLayer=Transx. TargetSpecies and Surveyors are pick lists for the Applet to use and should be populated prior to using the Applet. This file should be updated before taking your data to a survey. Either change the configuration file before transferring it to the GPS unit or, once the files are all transferred to the unit, copy it to your computer, change the values that need to be changed and then copy it back to the unit, overwriting the old configuration file.

\section{Applet installation}

To install the Applet, copy all files contained in the Applets folder to the Program Files/ArcPad/Applets folder on the mobile device. The Applet is installed by ArcPad on startup, so if ArcPad is running on the device, you will need to restart ArcPad after the files are copied to the mobile device.

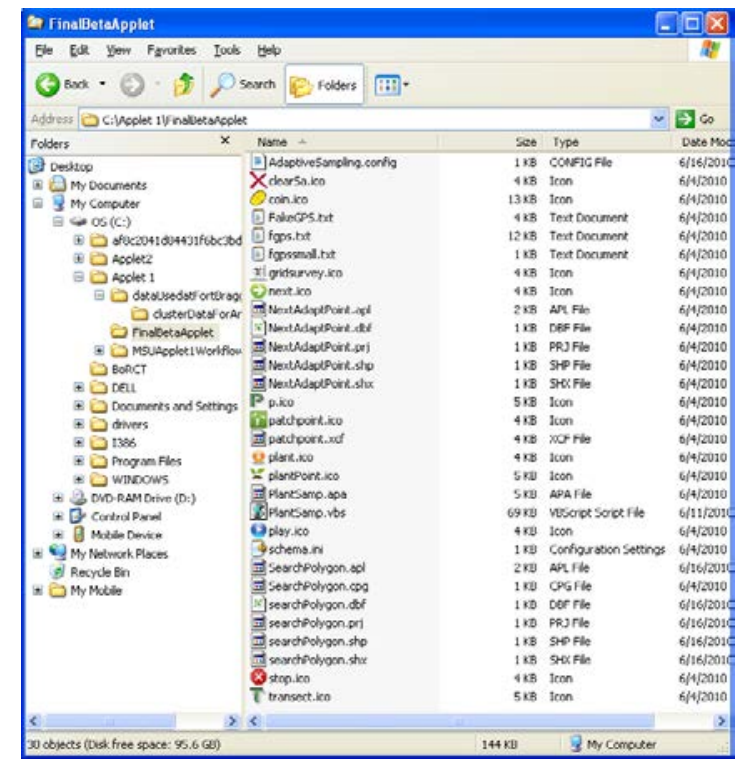


If the application is installed correctly, a new tool bar will appear within ArcPad.

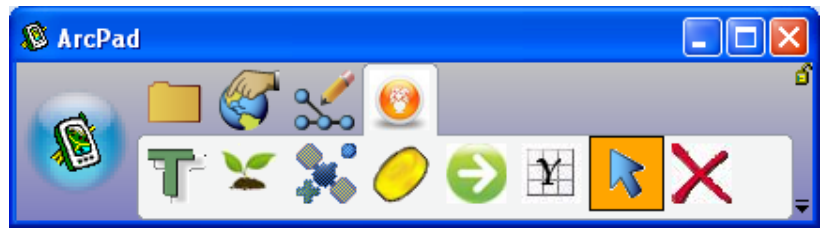




\section{Appendix B: FAQs and Tips}

\section{Q. Where can I get the applet software?}

A. The software is available from the Montana State University, Weed and Invasive Plant Ecology and Management Group website http:// weedeco.msu.montana.edu/rangewildland/index.html.

\section{Q. What is the benefit of using an adaptive sampling method?} A. Adaptive sampling is a useful way to locate additional populations of invasive plants that are rare but spatially clustered. Adaptive sampling, as guided by the applet, will help the surveyor focus their surveying efforts in areas where invasive plants are found.

\section{In what scenarios is the method expected to provide benefits over other standard approaches? This adaptive sampling method} provides a benefit when the invasive plants to be surveyed are relatively rare, but clustered, across the landscape. When the detection of one population triggers the launch of adaptive sampling, additional effort is spent adaptively searching for other populations in the vicinity of the found population. If, however, populations are ubiquitous across the landscape, adaptive sampling will provide no benefit because populations will be encountered regardless, and adaptive sampling will be excessively slow.

Can this method be used to survey more than one species at a time? No, this method was developed with the intent of sampling a single species at a time. Attempting to record multiple species will affect the Applet's ability to select random cells to be sampled and will negate the results of the survey.

How do I install the Applet on a GPS unit? Appendix B subsection b in the user's manual describes the process of installing the applets on a Trimble GPS unit. It is as simple as copying files into the correct directory on your mobile unit.

Will the Applet run on any GPS unit? This tool was developed for Trimble's GeoExplorer series of GPS units and is as yet untested on other platforms. While it may run on other platforms, the current testing has 
all been done on GeoExplorer 2008 units and using this Applet on another platform may yield less than satisfactory results.

How do I start a new sampling session? When starting a new transect or when finished with an adaptive sampling session, a new adaptive sampling session will begin with the recording of a new Adaptive Plant Patch or Adaptive Plant Point.

How do I record the presence of an invasive weed? Invasive plant presences are recorded by collecting point or polygon features along a transect. Section 3.3 illustrates in detail the differences of various types of features.

What do I do after I record the first invasive plant presence along a transect? After recording a presence along a transect, the Applet will generate additional cells to be sampled, but not on the transect. Following the Conduct a Survey methods prescribed in section 3.3 of the user's manual, provided with the Applet, begin sampling additional cells in accordance with the process described.

What if no invasive plants are present in the cell that I was led to adaptively sample? Simply mark the cell in question as absent and continue sampling the transect in accordance with section 3.3, Conduct a Survey.

What do I do if I see a population of invasive plants that are not in a transect cell that I am supposed to sample? Presences should only be recorded if they occur within the cell to be sampled, whether that is a transect cell or an adaptively selected cell. Recording information from neighboring cells will bias the results of the survey.

What if I sample the entire transect and no weed presences are recorded? The sampling session is over.

What do I do when the Max Search Area has been reached? If an initial Adaptive Plant Patch is collected and the boundary extends beyond the demarcated Max Search Area polygon, no adaptive sampling should take place. If, however, the initial polygon falls within the Max Search Area polygon, adaptive sampling will take place until all adaptive cells 
have been sampled within the Max Survey Area. See section 3.3 for detailed illustrations on how to conduct a survey.

What do I do when $A_{\max }$ has been reached? When the number of cells sampled equals the number set for $\mathrm{A}_{\max }$, adaptive sampling is finished. When the applet asks if you would like to continue, click "No" and return to the transect for additional sampling.

What do I do when the Max Survey Area has been reached? No sampling of any kind should take place beyond the boundary of the Max Survey Area. If a patch is being delineated that extends beyond this boundary the surveyor should instead follow the boundary of the Max Survey area rather than the actual patch boundary. No adaptive sampling should ever be done outside this polygon.

What do I do when $S_{\max }$ has been reached? If $S_{\max }$ is reached, then the total number of cells that you wish to sample has been reached and the survey is finished.

How do I choose appropriate values for $S_{\max }, A_{\max }$, and $P_{\text {sp }}$ ? These values will be specific to the species and landscape being surveyed and the goals of the survey. Therefore, a simple answer cannot be provided in this document. In general terms, however, $\mathrm{S}_{\max }$ is based on time considerations and the total amount of data needed; $\mathrm{A}_{\max }$ could be matched to the dispersal distance of the target species; and $\mathrm{P}_{\mathrm{sp}}$ could be related to the local habitat variability.

If I made a mistake in entering Present/Absent values, how do I edit them? Consult manual Appendix C subsection "Editing Features in ArcPad" to assist you in correcting any mistake made. Changing features using this applet requires some use of the native ArcPad toolsets and functions and therefore each anticipated scenario has been written into Appendix E to simplify the process of correcting a value mistake.

\section{What happens if I accidentally close ArcPad during the survey?}

In many cases, ArcPad saves any edits/ changes to the data without presenting a "Save Data" menu option. It has been observed that, if ArcPad is accidently closed, data are not lost. However, it is always best to save data regularly. 
How do I save the file after the survey has been completed?

When ArcPad is closed, it will present a "Save Data" menu option. Affirm save data and close.

When collecting a Transect Plant Point, do I have to enter a value for length? Transect Plant Points can be collected with an attribute for Start, Middle, or End. When recording a Transect Plant Point as a middle point, values for length and width are important for determining the extent of the patch. However, when recording a Transect Plant Point as a start point, length of the patch is not important because every start point should be paired with an end point from which length can be calculated. In this scenario, patch length should be entered as a value of 999 or some other value that will be understood to be $<$ Null $>$. 


\section{Appendix C: File Reference}

The following files and folders are included for use with the RTAC method:

- A folder called AdaptiveSamplingTools

- A folder called Documentation

- A folder called Adaptive_Cluster_Applet

- An empty geodatabase schema in the correct format containing all required fields and attributes.

A brief description of each follows.

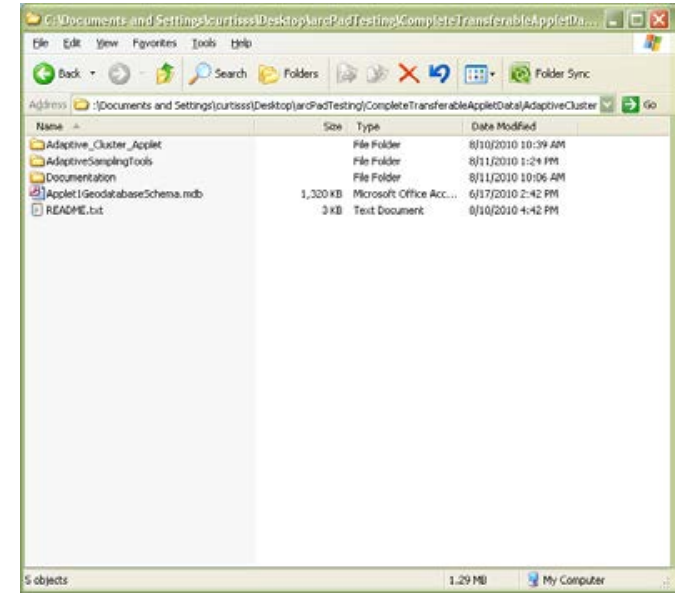

\section{AdaptiveSamplingTools}

This folder contains an ESRI tool box file called Adaptive_Sampling_Tools.tbx as well as two scripts to be used for the construction of data in the geodatabase. To access the tools these scripts belong to, open ArcMap and right click in the Toolbox window, choosing the menu Add Toolbox. Correctly define the location of the Adaptive_Sampling_ Tools.tbx at the location where you have chosen to keep the .tbx file. This location can be within the AdaptiveCluster folder as provided, or at another location. Be sure to keep the PYTHON script files in the same folder as the .tbx file. If they are separated, the tools stored paths will not be correct and the tools will not work. Should this happen, verify that the script paths are correct. Once the toolbox is added to the toolbox window, two script tools will appear: Corridor Builder and Survey Grid Builder. Double click on either of these tools to access their functionality.

\section{Documentation}

This folder contains all of the documentation that was provided with the Applet. It includes users' guides, tips, and methods for all of the processes that must be completed to utilize this method of sampling and to properly prepare data for use by the Applet. This documentation proceeds step by step through the majority of the processes required by the Applet. It is 
recommended this documentation be read before using the Applet and kept available for future reference.

\section{Adaptive_Cluster_Applet}

Contains all of the files required to run the Applet on the GPS unit. From this folder, Copy/ Paste the files into the Program Files/ArcPad/Applets folder on the GPS.

\section{Applet1GeodatabaseSchema.mdb}

This is the empty geodatabase that has been prepared for this Applet. It contains all of the correct layers, fields, and attributes required for the Applet to function properly. It is recommended to make a backup of this .mdb before making any changes. If the original is lost, or for any reason it becomes necessary to build a new geodatabase, a table is included in the documentation provided illustrating the proper layout and required fields of the geodatabase. 


\section{Appendix D: Geodatabase Schema}

\begin{tabular}{|c|c|c|c|c|c|}
\hline \multicolumn{6}{|l|}{ Personal Data Base Design } \\
\hline \multirow{2}{*}{\multicolumn{6}{|c|}{ Geodatabase Name: User Defined }} \\
\hline & & & & & \\
\hline Domain Name & Domain Type & Field Type & \multicolumn{3}{|c|}{ Values (If only one listed, then coded equals description). } \\
\hline NIS_Species & coded & text & \multicolumn{3}{|c|}{ User Defined } \\
\hline Percent_Cover & range & long integer & \multicolumn{3}{|c|}{$0-100$} \\
\hline Patch_Density & coded & text & \multirow{2}{*}{\multicolumn{3}{|c|}{$\begin{array}{l}<0-1,1-11,12-32,33-100,101-316,317-1000,>1000 \\
\text { ind/scattered plants, discrete patches, interconnected patches }\end{array}$}} \\
\hline Patch_Pattern & coded & text & & & \\
\hline Surveyor & coded & text & \multirow{2}{*}{\multicolumn{3}{|c|}{$\begin{array}{l}\text { User Defined } \\
\text { Start, End }\end{array}$}} \\
\hline \multirow[t]{2}{*}{ StartEnd } & coded & text & & & \\
\hline & \multicolumn{5}{|c|}{ Feature Dataset Name: surveyGPSFeatures } \\
\hline Feature Class Name & Geometry Type & Field Name & Data Type & Domain Name & Values \\
\hline transect & point & start_end & text & Startend & see domain \\
\hline & & surveyor 1 & text & Surveryor & see domain \\
\hline & & surveyor2 & text & Surveryor & see domain \\
\hline & & id & text & none & Length $=25$ \\
\hline & & ave_accuracy & double & none & none \\
\hline & & worst_accuracy & double & none & none \\
\hline & & target_species & text & NIS_Species & see domain \\
\hline & & gpsdate & date & none & none \\
\hline & & TRANSECTID & text & none & Length $=30$ \\
\hline adapt_plant_pnt & point & target_species & text & NIS_Species & see domain \\
\hline & & Percent_Cover & long integer & Percent_Cover & see domain \\
\hline & & Patch_Density & text & Patch_Density & see domain \\
\hline & & Patch_Pattern & text & Patch_Pattern & see domain \\
\hline & & Comment & text & none & Length $=50$ \\
\hline & & ave_accuracy & double & none & none \\
\hline & & worst_accuracy & double & none & none \\
\hline & & TRANSECTID & text & none & Length $=30$ \\
\hline adapt_plant_patch & polygon & target_species & text & NIS_Species & see domain \\
\hline & & Percent_Cover & long integer & Percent_Cover & see domain \\
\hline & & Patch_Density & text & Patch_Density & see domain \\
\hline & & Patch_Pattern & text & Patch_Pattern & see domain \\
\hline & & Comment & text & none & Length $=50$ \\
\hline & & ave_accuracy & double & none & none \\
\hline & & worst_accuracy & double & none & none \\
\hline & & TRANSECTID & text & none & Length $=30$ \\
\hline & & SHAPE_Length & double & none & none \\
\hline & & SHAPE_Area & double & none & none \\
\hline transect_plant_pnt & point & target_species & text & NIS_Species & see domain \\
\hline & & Percent_Cover & long integer & Percent_Cover & see domain \\
\hline & & Patch_Density & text & Patch_Density & see domain \\
\hline & & Patch_Pattern & text & Patch_Pattern & see domain \\
\hline & & Comment & text & none & Length $=50$ \\
\hline & & ave_accuracy & double & none & none \\
\hline & & worst_accuracy & double & none & none \\
\hline & & TRANSECTID & text & none & Length $=30$ \\
\hline & & POSITION_ & text & none & Length $=15$ \\
\hline & & LENGTH & float & none & none \\
\hline & & WIDTH & float & none & none \\
\hline generic_pnt & point & Comment & text & none & Length $=50$ \\
\hline & & ave_accuracy & double & none & \\
\hline & & worst_accuracy & double & none & \\
\hline generic_line & line & Comment & text & none & Length $=50$ \\
\hline & & ave_accuracy & double & none & none \\
\hline & & worst_accuracy & double & none & none \\
\hline & & SHAPE_Length & double & none & none \\
\hline generic_poly & polygon & Comment & text & none & none \\
\hline & & ave_accuracy & double & none & none \\
\hline & & worst_accuracy & double & none & none \\
\hline & & SHAPE_Length & double & none & none \\
\hline & & SHAPE_Area & $\begin{array}{l}\text { double } \\
\end{array}$ & none & none \\
\hline surveyGrid & grid & Id & long integer & none & none \\
\hline & & Status & text & none & Length $=25$ \\
\hline & & scode & short integer & none & none \\
\hline & & SHAPE_Length & double & none & none \\
\hline & & SHAPE_Area & double & none & none \\
\hline Transect_Corridor & polygon & Id & long integer & none & none \\
\hline & & BUFF_DIST & long integer & none & none \\
\hline & & SHAPE_Length & double & none & none \\
\hline & & SHAPE_Area & double & none & none \\
\hline Transectline & line & Id & long integer & none & none \\
\hline & & Shape_Length & double & none & none \\
\hline
\end{tabular}




\section{Appendix E: Applet Operation}

\section{Starting the Applet}

The Applet is automatically loaded by ArcPad when the application is started. A new tool bar will appear in ArcPad when the Applet is properly installed.

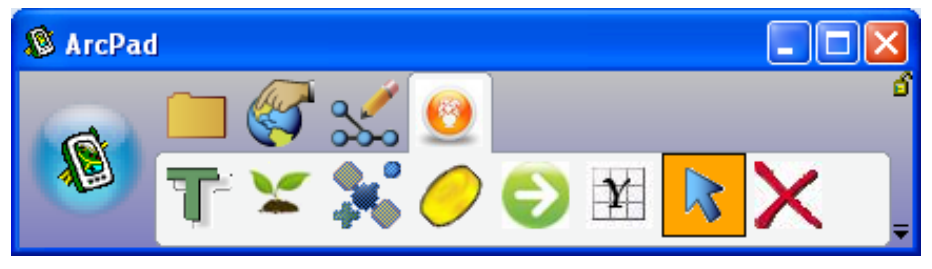

\section{Capture transect point}

Transect points are created to define start and end points of a transect; click the Capture Transect Point button i to create a start or end point for the transect. If the GPS is active, the data collection form is shown; if the GPS is not active, a dialog window will appear asking you to turn it on. The data collection form for a transect point follows:

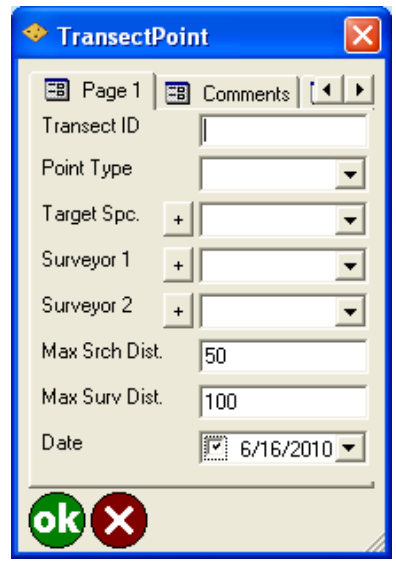

\section{Capture adaptive plant point}

Adaptive plant points are used for capturing and attributing individual plants or small patches. Click the Capture Adaptive Plant Point button - to display the data collection form. 

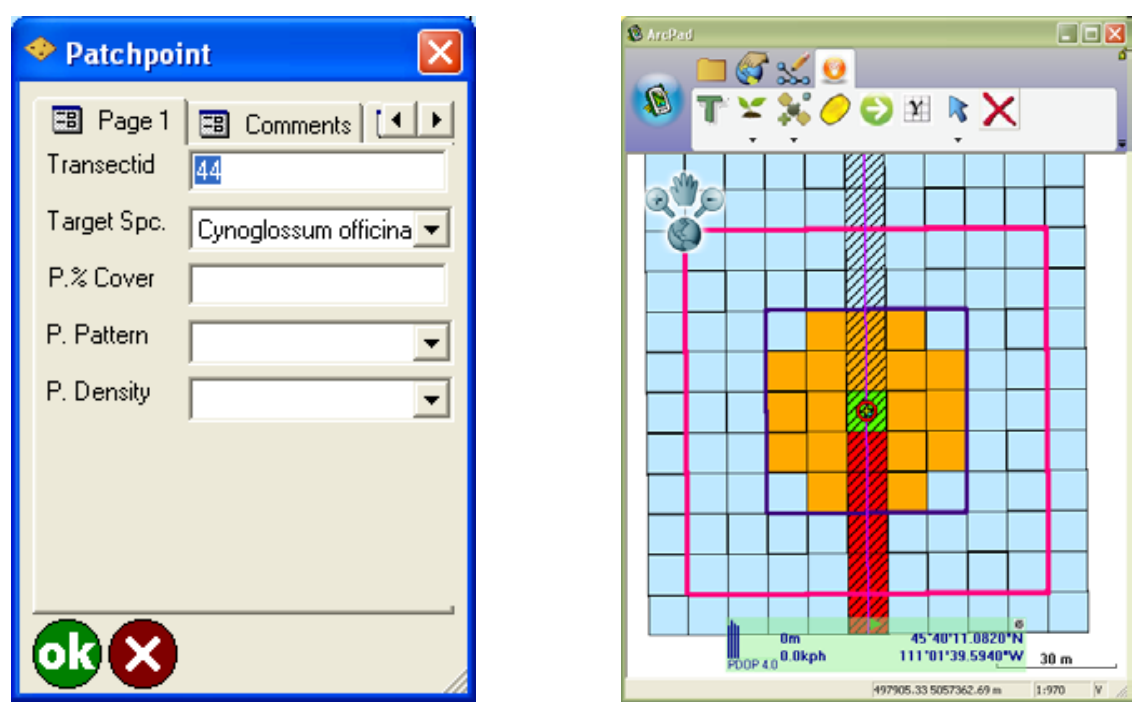

When an adaptive plant point is created, the maximum survey area and maximum search area are delineated on the screen as shown above in pink and purple. The current grid cell is selected based on the plant point location and marked as surveyed/present (as shown above). Orange cells in the above example are marked as Need to Sample based on the search tolerances.

\section{Capture Adaptive Plant Patch}

Adaptive plant patches are used for capturing larger plant patch boundaries and their attributes. After clicking the Capture Adaptive Plant Patch button $\$$, use ArcPad tools to capture vertices. When finished the data collection form appears.
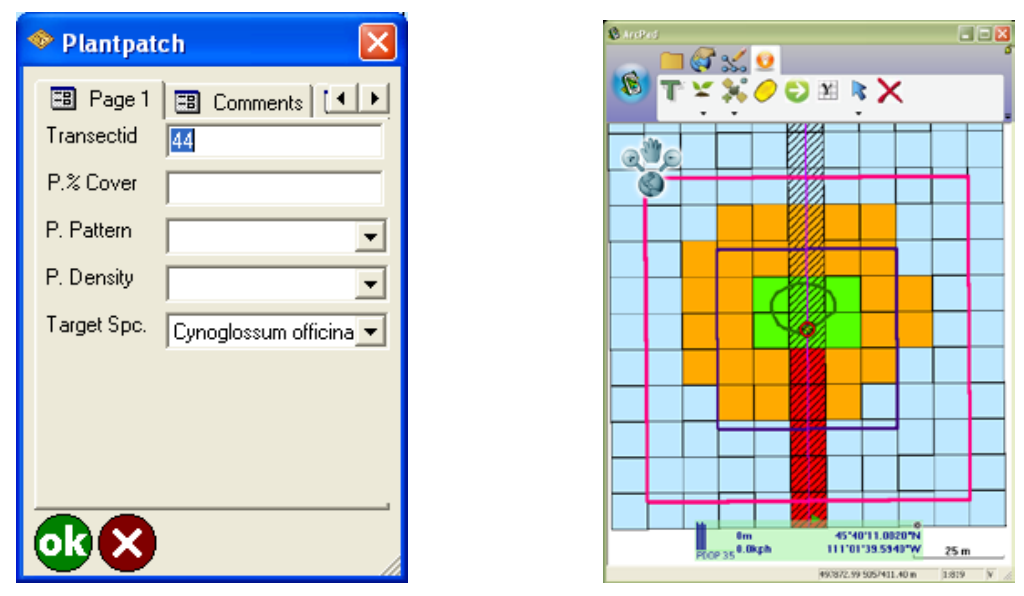
Use the Capture Vertex button to add vertices while walking the patch perimeter.

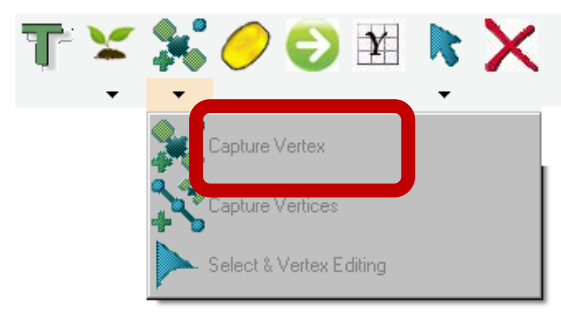

Once the patch has been mapped, use the green arrow in the bottom left of the screen to finish and close the polygon.

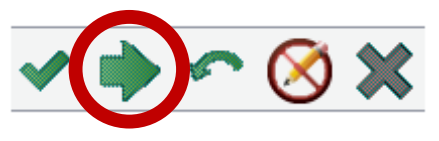

When an adaptive plant patch is created, each grid cell that is within the polygon boundary is marked as sampled/ present (green in the screen shot at bottom of preceding page). Additional grid cells are selected based on the search tolerances and marked as Need to Sample (orange).

\section{Capture Transect Plant Point}

A transect plant point is used to mark plant features that do not require adaptive sampling, such as when between adaptive search areas. With a GPS position fix, click the Capture Transect Plant Point button $\%$ to mark the location and show the data collection form shown below. If the patch to be marked with a transect plant point is small enough, simply select Middle under the Position dropdown menu and enter all the attribute values. If the patch is large (i.e., you cannot see the opposing patch boundary), select Start under the Position drop down and enter a value of 0 for the length. Also, enter values for the other attributes. When you reach the opposing boundary, click the Capture Transect Plant Point button $\%$ again to mark the end location of the

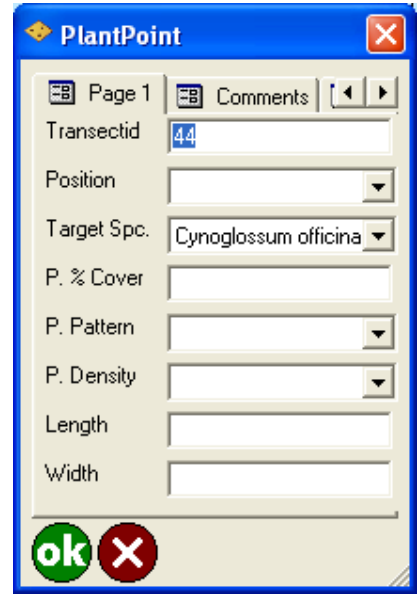
patch and open the data collection form. This time select End under the Position drop-down menu, enter a value of 0 for the length, and enter 
values for the remaining attributes. The start and end positions can be used later, within ArcGIS, to calculate the patch length.

\section{Coin Toss}

The Coin Toss button $O$ is used before adaptively sampling grid cells to indicate the direction the user should begin sampling.

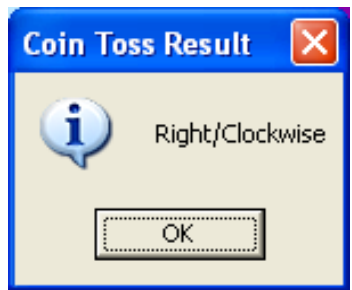

\section{Draw Next Adaptive Search Area}

The Draw Next Adaptive Search Area button $\rightarrow$ is used to draw the indicator for where to begin using adaptive sampling methods. At the start of a transect, use the Clear Max Survey Area button and begin sampling along the transect. The maximum adaptive search area will automatically draw when an adaptive plant point or patch is recorded. After finishing an adaptive sampling session, the Draw Next Adaptive Search Area button should be selected to draw the indicator for the next location to be adaptively sampled.

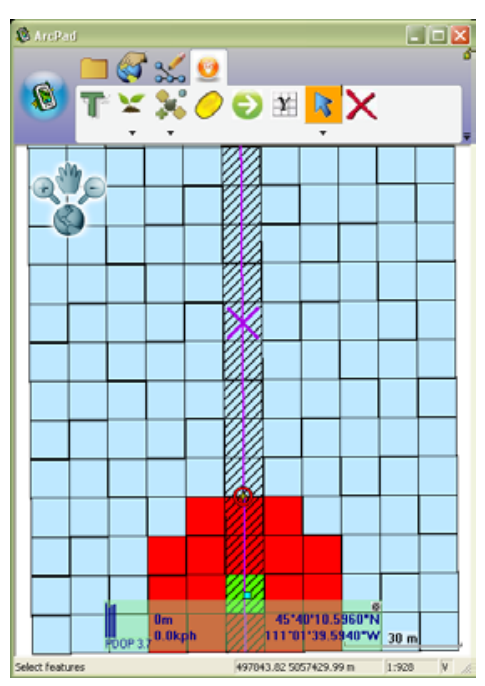

\section{Update Current Grid Cell}

The Update Grid Cell button $Y$ is used to sample grid cells based on the current GPS location. Cells are automatically selected from the current GPS location, and a form is presented to update the grid attributes. 

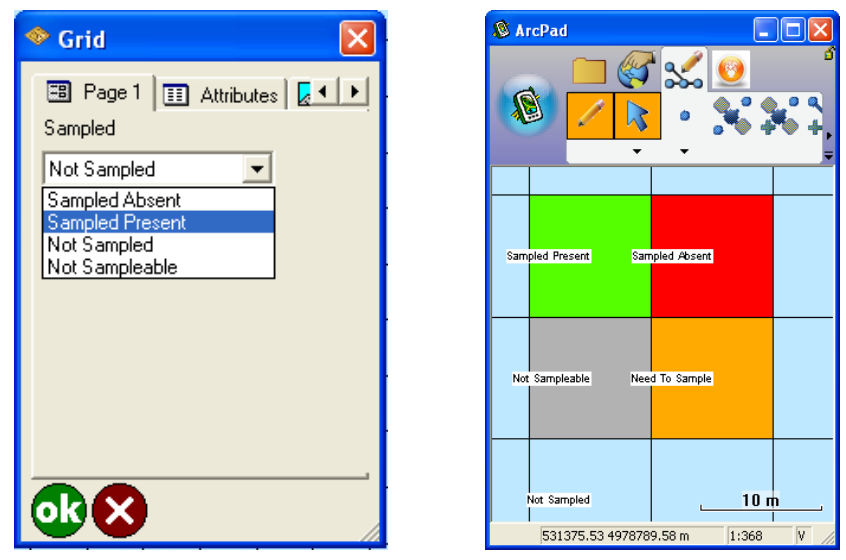

Updating the grid changes the color of the grid cell to visually indicate the status of the grid location. There are five different values for the grid cells: $0=$ Sampled/ Absent (red); $1=$ Sampled/Present (green); $3=$ Need to Sample (orange); 2 =Not Sampled (blue default value); and $-9=$ Not Sampleable.

\section{Clear Max Survey Area}

The Clear Max Survey Area button X will delete the current maximum survey and maximum search areas displayed on the map. This tool also sets a flag to draw the maximum survey area next time an adaptive point feature is created.

\section{Editing features in ArcPad}

For various reasons, the survey crew may find it necessary to change features while in the field. Examples of this may include instances where the survey crew finds that they have missed a target plant or have misidentified a plant and included it in the survey. The following steps outline the proper methods to update and change features and/ or previously sampled cells.

> Changing Sampled Present to Sampled Absent

\section{Transect Plant Point}

Use the Select button on the Applet toolbar to select and then use the Delete button to delete the point. 


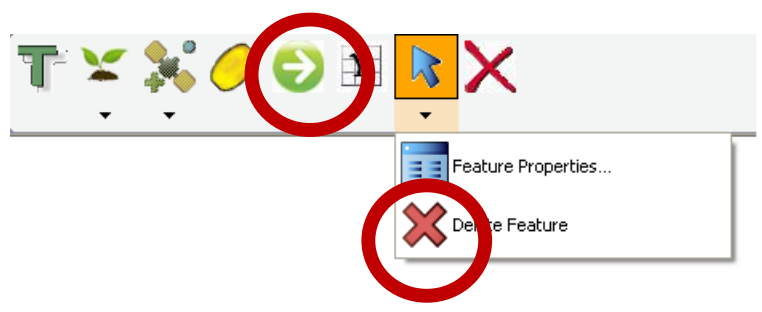

Once the point is deleted, use the Update Current Grid Cell button to change the cell where the Transect Plant Point was mistakenly captured from Present (green) to Absent (red).

\section{Adaptive Plant Point}

Use the Select button under the Applet toolbar and select and delete the point. Once the point is deleted, use the Update Current Grid Cell button to change the cell in which the Plant Point was gathered from present (green) to absent (red). The Applet will not automatically change the selected adaptive cells to Not Sampled, but they do not need to be manually changed because at the next present location the Applet will select new adaptive cells and clear the mistaken ones.

\section{Adaptive Plant Patch}

Use the Select and Vertex Edit button to do one of two things:

- Erase the feature: When a complete feature is deleted, the adaptive cells will be updated when another presence is recorded. The cells that are automatically changed to Present (green) within a polygon that is deleted must be manually reset to Not Sampled. If these cells are not manually changed, they will be unavailable for future adaptive selection.

- Move vertices: Use the Select and Vertex Edit button and move the necessary vertices to show the actual patch boundary. The Applet will automatically update the adaptive cells. 


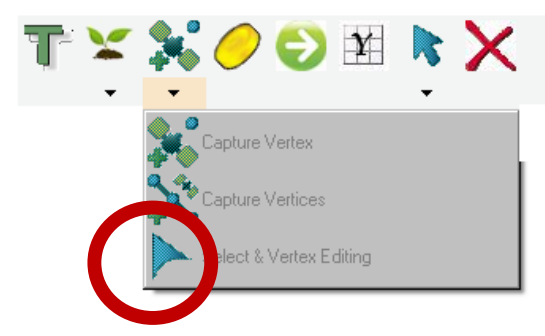

Once the vertices are in the correct location, use the green checkmark in the lower left corner of the screen to accept the changes and finish the new polygon.

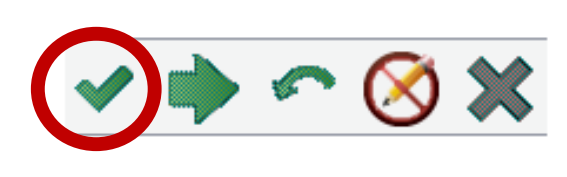

> Changing Sampled Absent to Sampled Present

\section{Transect Plant Point}

In the cell that has been mistakenly marked Sampled Absent, collect a Transect Plant Point using the Capture Transect Plant Point button $\mathcal{*}$. Fill in all the fields in the data collection form and continue sampling. The Applet will update the cell to Sampled Present.

\section{Adaptive Plant Point}

In the cell that has been mistakenly marked Sampled Absent, collect an Adaptive Plant Point using the Capture Adaptive Plant Point button - Fill in all the fields in the data collection form and continue sampling. The Applet will update the cell to Sampled Present, and will display the appropriate cells to adaptively sample.

\section{Adaptive Plant Patch}

If no Adaptive Plant Patch feature has been captured, collect an Adaptive Plant Point using the Adaptive Plant Patch button " $r$. Fill in all the fields in the data collection form and continue sampling. The Applet will update the appropriate cells to Sampled Present, choose the cells to adaptively sample, and display them accordingly. 
If an Adaptive Plant Patch has been captured, but you would like to adjust the boundary of the patch, use the Select and Vertex Edit button to move vertices in an existing patch to reflect the true boundary of the patch. Once the vertices are in the correct location, use the green checkmark in the lower left corner of the screen to accept the changes and finish the new polygon.

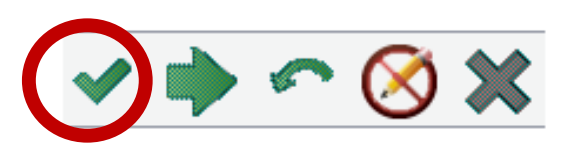

> The Applet will adjust the cells surrounding the new edited version of the Adaptive Plant Patch boundary appropriately. 


\section{Appendix F: Applet Buttons Quick Reference}

Table F1. Buttons on the Applet main toolbar

\begin{tabular}{|c|c|c|}
\hline$\overline{4}$ & Capture Transect Point & $\begin{array}{l}\text { Create GPS point feature for start/end } \\
\text { transect }\end{array}$ \\
\hline-0 & Capture Adaptive Plant Point & Create GPS point feature for plant \\
\hline & Capture Adaptive Plant Patch & Create GPS polygon feature for area \\
\hline & Capture Transect Plant Point & Create GPS point feature for transect point \\
\hline & Capture Vertex & ArcPad tool to capture vertex \\
\hline & Capture Vertices & ArcPad tool to capture streaming vertices \\
\hline & Select \& Vertex Editing & ArcPad tool to edit polygon vertices \\
\hline & Coin Toss & Tool to tell user which direction to survey \\
\hline & Draw Next Adaptive Search Unit & $\begin{array}{l}\text { Draw next available search unit based on } \\
\text { current GPS location }\end{array}$ \\
\hline Y & Update Current Grid Cell & $\begin{array}{l}\text { Selects cell for updating based on current } \\
\text { GPS position }\end{array}$ \\
\hline B & Select & ArcPad tool to select editable features \\
\hline & Feature Properties & ArcPad tool to show feature attributes \\
\hline & Delete Feature & ArcPad tool to delete selected feature \\
\hline & Clear Max Survey Area & $\begin{array}{l}\text { Clears (deletes) current maximum survey } \\
\text { area }\end{array}$ \\
\hline Help & $\begin{array}{l}\text { Located under the Capture } \\
\text { Transect Point button }\end{array}$ & Brings up the help menu for the Applet \\
\hline
\end{tabular}


Public reporting burden for this collection of information is estimated to average 1 hour per response, including the time for reviewing instructions, searching existing data sources, gathering and maintaining the data needed, and completing and reviewing this collection of information. Send comments regarding this burden estimate or any other aspect of this collection of information, including suggestions for reducing this burden to Department of Defense, Washington Headquarters Services, Directorate for Information Operations and Reports (0704-0188), 1215 Jefferson Davis Highway, Suite 1204, Arlington, VA 22202-4302. Respondents should be aware that notwithstanding any other provision of law, no person shall be subject to any penalty for failing to comply with a collection of information if it does not display a currently valid OMB control number. PLEASE DO NOT RETURN YOUR FORM TO THE ABOVE ADDRESS.
1. REPORT DATE (DD-MM-YYYY)
2. REPORT TYPE
3. DATES COVERED (From - To)

30 September 2011

Final

4. TITLE AND SUBTITLE

Random Transect with Adaptive Clustering Sampling Design - ArcPad Applet

Manual

6. AUTHOR(S)

Vickie M. Backus, Lisa J . Rew, Bruce D. Maxwell, and Matthew G. Hohmann

5a. CONTRACT NUMBER

5b. GRANT NUMBER

5c. PROGRAM ELEMENT

A896

5d. PROJECT NUMBER

030F25

5e. TASK NUMBER

5f. WORK UNIT NUMBER

7. PERFORMING ORGANIZATION NAME(S) AND ADDRESS(ES)

8. PERFORMING ORGANIZATION REPORT NUMBER

US Engineer Research and Development Center, Construction Engineering Research

Laboratory

PO Box 9005

Champaign, IL 61826-9005

Department of Land Resources and

Environmental Science

ERDC/CERL TR-11-32

Montana State University

PO Box 173120

Bozeman, MT 59717-3120

\section{SPONSORING I MONITORING AGENCY NAME(S) AND ADDRESS(ES)}

Department of the Army

Office of the Director of Environmental Programs

600 Army Pentagon

Washington, DC 20310-0600

11. SPONSOR/MONITOR'S REPORT NUMBER(S)

\section{DISTRIBUTION I AVAILABILITY STATEMENT}

Approved for public release; distribution is unlimited.

\section{SUPPLEMENTARY NOTES}

\section{ABSTRACT}

Non-native invasive plant species (NIS) pose a significant threat to native biological diversity. Their management and control are mandated by Executive Order 13112 on all federal lands in the United States, including Army training lands.

A key component of any NIS management strategy is knowing the distribution of NIS across the management landscape. Survey or sampling methods are often needed because Army installations are too large to inventory completely. Efficient sampling is crucial because early-detection, rapid-response management approaches rely on detection of newly established (but rare) NIS populations. Adaptive sampling is an alternative to conventional sampling that capitalizes on the spatial clustering of biological populations. Adaptive sampling has the potential to be efficient at sampling rare and clustered populations, but its use has been limited by a lack of tools to aid implementation in the field.

This manual describes an adaptive cluster sampling design called the Random Transect with Adaptive Clustering Sampling Design (RTAC) and a user-friendly global positioning system (GPS) interface developed to aid implementation of the sampling design in the field. The GPS user interface described here is a customized application developed for ESRI's ArcPad® mobile geographical information software (GIS) for field applications.

\section{SUBJECT TERMS}

non-native invasive plant species (NIS), adaptive sampling, Random Transect with Adaptive Clustering (RTAC), ArcPad, global positioning system (GPS), georgraphical information software (GIS)

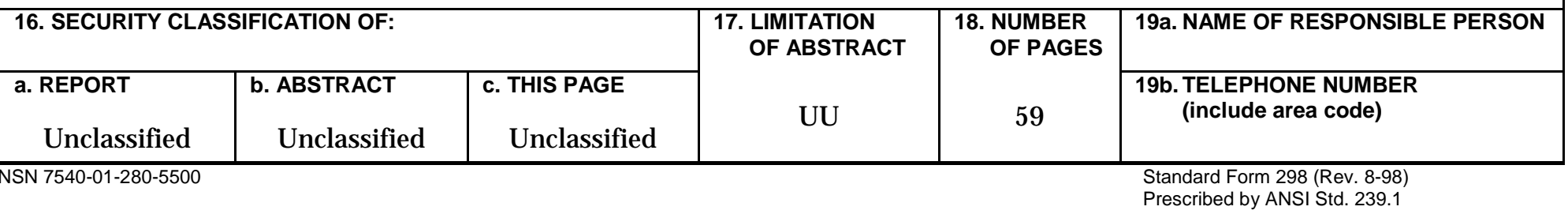

